\title{
A Business Case for Advanced Outage Management
}

Ken Thomas

Sean Lawrie Josef M. Niedermuller

March 2016

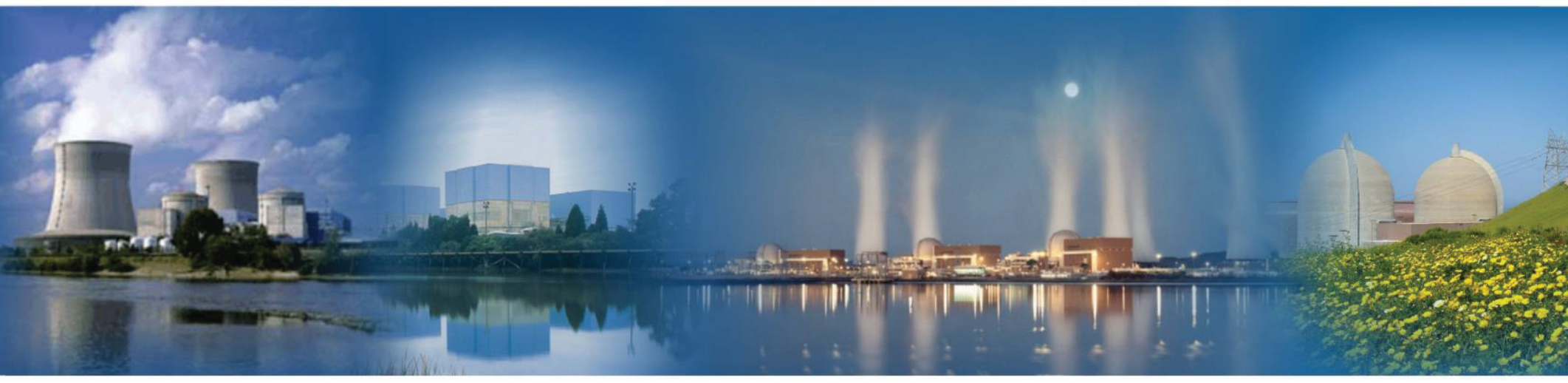

U.S. Department of Energy Office of Nuclear Energy 


\section{DISCLAIMER}

This information was prepared as an account of work sponsored by an agency of the U.S. Government. Neither the U.S. Government nor any agency thereof, nor any of their employees, makes any warranty, expressed or implied, or assumes any legal liability or responsibility for the accuracy, completeness, or usefulness, of any information, apparatus, product, or process disclosed, or represents that its use would not infringe privately owned rights. References herein to any specific commercial product, process, or service by trade name, trade mark, manufacturer, or otherwise, does not necessarily constitute or imply its endorsement, recommendation, or favoring by the U.S. Government or any agency thereof. The views and opinions of authors expressed herein do not necessarily state or reflect those of the U.S. Government or any agency thereof. 
INL/EXT-16-38265

\title{
A Business Case for Advanced Outage Management
}

\author{
Ken Thomas \\ Idaho National Laboratory \\ Sean Lawrie \\ Josef M. Niedermuller \\ ScottMadden, Inc.
}

March 2016

\section{Idaho National Laboratory \\ Light Water Reactor Sustainability Program \\ Advanced Instrumentation, Information, and Control Systems \\ Technologies \\ Idaho Falls, Idaho 83415}

http://www.inl.gov

Prepared for the

U.S. Department of Energy

Office of Nuclear Energy

Under DOE Idaho Operations Office

Contract DE-AC07-05ID14517 



\section{SUMMARY}

Department of Energy's (DOE’s) Light Water Reactor Sustainability Program (LWRS) develops technologies that will make the existing U.S.A. nuclear fleet more efficient and competitive. The program has developed a standard methodology for determining the impact of new technologies in order to assist nuclear power plant (NPP) operators in building sound business cases.

This paper presents a generic business case for implementation of technology that supports Advanced Outage Management (AOM). The analysis presented is built upon and incremental to a prior business case created for Mobile Work Packages (MWP). The business case demonstrates that advanced communication and networking and analytical technologies will allow NPP to conduct outages with fewer people in management roles and the remaining people can be more effective and more productive. The benefits are quantified to a rough order of magnitude that provides directional guidance to NPPs that are interested in developing a similar business case.

AOM is enabled by a suite of technologies, which are described in further detail in the body of this report. They include:

- High-bandwidth wireless networks

- Mobile devices

- Component identification technology

- Mobile wireless video cameras

- Touch enabled interactive displays

- Computer-Based Procedures (CBP)/automated work packages

- Intelligent plant configuration

- Advanced data analytics

- Micro-scheduling

- Meeting collaboration tools

- Team collaboration tools

An analysis was conducted to determine how these technologies might impact outage operations at an NPP. The analysis concluded that outage management capabilities would be improved with application of these technologies, and result in annual benefits for the plant. These improved capabilities were identified and described in further detail in this report.

- Automated status updates

- Advanced bulk work and schedule analysis

- Networked meetings (remote access)

- Networked emergent work teams

- Coordination of dispatchable resources

- Outage configuration management

- Remote job oversight

- Paperless outage coordination 
- Bulk work optimization

Further analysis was conducted to quantify the potential savings for the NPP using a Business Case Methodology (BCM) developed by INL in conjunction with ScottMadden Inc., a management consulting firm prominent in energy markets, particularly in the nuclear generation industry.

The resulting business case demonstrates substantial benefits in both labor and non-labor categories with the application of AOM as illustrated in the table below:

\section{Combined Business Case (MWP and AOM)}

\begin{tabular}{|lcc|}
\hline Discount Rate (Internal Rate of Return): & & $10 \%$ \\
No. Years of Benefit: & & 15 years \\
Annual Benefit (Labor) & $\$$ & 5.91 million \\
Annual Benefit (Non-Labor) & $\$$ & 1.88 million \\
Annual Benefit (KPI) & & $n / a$ million \\
\cline { 2 - 3 } Total Annual Benefit: & $\$$ & 7.79 \\
First Year Realized Benefit: & & \multicolumn{2}{c}{3} \\
Estimated Net Zero NPV Investment: & & $\$ 48.96$ million \\
\hline
\end{tabular}

In addition to cost savings, these technologies also offer improvements to human performance and key performance indicators (KPIs) of the plant. Through publication of the findings and the BCM, the nuclear industry is provided with a sample business case for pilot project technologies that can be used as a template for pursuing similar implementations at other nuclear plants. 


\section{FOREWORD}

Department of Energy's (DOE's) Light Water Reactor Sustainability Program (LWRS) develops technologies that will make the existing U.S.A. nuclear fleet more efficient and competitive.

The Advanced Instrumentation, Information, and Control (II\&C) Systems Technologies Pathway is part of LWRS Program. It conducts targeted research and development (R\&D) to address aging and reliability concerns with the legacy instrumentation and control and related information systems of the U.S. operating light water reactor (LWR) fleet. This work involves two major goals: (1) to ensure that legacy analog II\&C systems are not life-limiting issues for the LWR fleet and (2) to implement digital II\&C technology in a manner that enables broad innovation and business improvement in the NPP operating model. Resolving long-term operational concerns with the II\&C systems contributes to the long-term sustainability of the LWR fleet, which is vital to the nation's energy and environmental security.

The II\&C Pathway is conducting a series of pilot projects that enable the development and deployment of new II\&C technologies in existing nuclear plants. Through the LWRS program, individual utilities and plants are able to participate in these projects or otherwise leverage the results of projects conducted at demonstration plants.

The pilot projects conducted through this program serve as stepping stones to achieve longer-term outcomes of sustainable II\&C technologies. They are designed to emphasize success in some crucial aspect of plant technology refurbishment and sustainable modernization. They provide the opportunity to develop and demonstrate methods to technology development and deployment that can be broadly standardized and leveraged by the commercial nuclear power fleet.

Performance advantages of the new pilot project technologies are widely acknowledged, but it has proven difficult for utilities to derive business cases for justifying investment in these new capabilities. Lack of a business case is often cited by utilities as a barrier to pursuing wide-scale application of digital technologies to nuclear plant work activities. The decision to move forward with funding usually hinges on demonstrating actual cost reductions that can be credited to budgets and thereby truly reduce O\&M or capital costs. Technology enhancements, while enhancing work methods and making work more efficient, often fail to eliminate workload such that it changes overall staffing and material cost requirements. It is critical to demonstrate cost reductions or impacts on non-cost performance objectives in order for the business case to justify investment by nuclear operators. For these reasons, the LWRS has created a standard methodology for determining the impact of new technologies in order to assist NPP operators in building sound business cases.

A Business Case Methodology (BCM) has been developed with the assistance of ScottMadden, Inc., a management consulting company to provide a structure for building the business case for adopting pilot project technologies in a manner that captures the total organizational benefits that can be derived from the improved work methods [1].. This includes the direct benefit to targeted work processes, efficiencies gained in related work processes, and avoided costs through the improvement of work quality and reduction of human error. 
The BCM is designed to addresses the "benefit" side of the analysis - as opposed to the cost side, and how the organization evaluates discretionary projects (Net Present Value (NPV), accounting effects of taxes, discount rates). The cost and analysis side is not particularly difficult for the organization and can usually be determined with a fair amount of precision (not withstanding implementation project cost overruns). It is in determining the "benefits" side of the analysis that utilities have more difficulty in technology projects and that is the focus of this methodology. The methodology is presented in the context of the entire process, but the tool provided is limited to determining the organizational benefits only.

This BCM approaches building a business case for a particular technology or suite of technologies by detailing how they impact an operator in one or more of the three following areas: Labor Costs, NonLabor Costs, and Key Performance Indicators (KPIs). Key to those impacts is identifying where the savings are "harvestable," meaning they result in an actual reduction in headcount and/or cost.

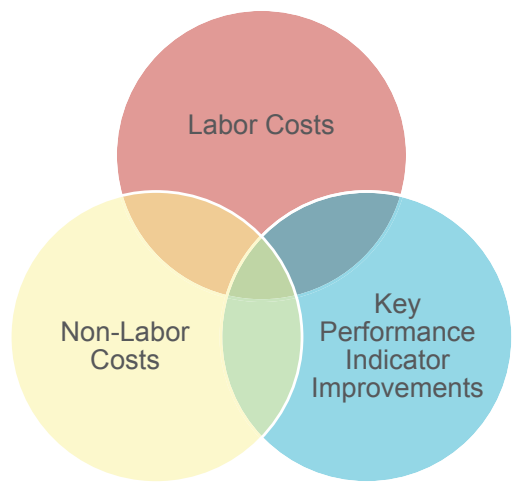

Figure 1: Key Areas of Impact

Impacts to NPPs in these three areas should be quantified and built into a comprehensive business case for the adoption of a technology.

Specifically, the BCM highlights key questions to ask and to guide the utility through, as well as identifies where in the process to employ the Business Case Methodology Workbook (BCMW) for benefits/cost savings identification. The approach enables collaboration between the II\&C Pathway and utility partners in applying new digital technologies across multiple NPP organizations and their respective work activities, wherever there is opportunity to derive benefit. In this manner, the BCM drives an "economy of scale" that maximizes the value of the technologies relative to the implementation cost.

The BCM leverages the fact that, in spite of what seems to be a wide and disparate array of work activities among an NPP's operational and support organizations, the work activities themselves are largely composed of common tasks. For example, whether the work activities are in Operations, Chemistry, Radiation Protection, or even Security, they have in common such tasks as pre-job briefs, use of procedures, correct component identification, emergent conditions requiring work package alteration, etc. It is at this task level that the technologies are applied, and therefore the benefits of the technologies can be realized across as many plant activities as can be identified to employ these tasks. In this manner, a much more comprehensive business case can be derived that greatly increases the benefit/cost ratio. This 
has the added benefit of driving consistency across the NPP organizations, which is a fundamental principle of successful NPP operational and safety management.

In May of 2015, the BCM was utilized to evaluate a suite of technologies being demonstrated by the LWRS program [2]. The pilot technology evaluated in this study was titled as MWP, which includes Computer Based Procedures (CBP) and other automated elements of the work package. This technology enables time savings through features such as smart place-keeping, smart branching, conflict detection and resolution, and seamless transition to other procedures. These features reduce the overhead, conflicts, and switching costs associated with executing procedures across a complex organization.

During the analysis, several improvements were incorporated in the BCMW, including means to estimate cost of labor savings, as well as a Present Value (PV) estimating tool to summarize the benefit of the technology in present terms. The tool is not intended to replace a thorough financial analysis of the project for investment, but rather to provide guidance that is reasonably accurate and directionally correct and inform whether or not to move to project into the next stage of development.

This project expands the business case prepared for MWP to include AOM. AOM focuses on efficiencies created by a suite of technologies when applied to outage management processes. It is established through work analysis that a considerable amount of time during outages is spent monitoring field activities, gathering information, analyzing plans and schedules, and redirecting workforce in order to achieve outage objectives. It is hypothesized that modernizing the tools available to managers and field teams alike can eliminate much of the manual communications and analysis much in the way that technologies allow us to perform tasks like calling a cab or depositing a check in our everyday lives.

It is important to note that the business case for AOM depends heavily on functionality introduced by MWP to be present. Therefore, this business case will present the total benefits of a combined business case (MWP and AOM), with the incremental benefit of AOM highlighted. Figure 2 illustrates the relationship between the two business cases. 


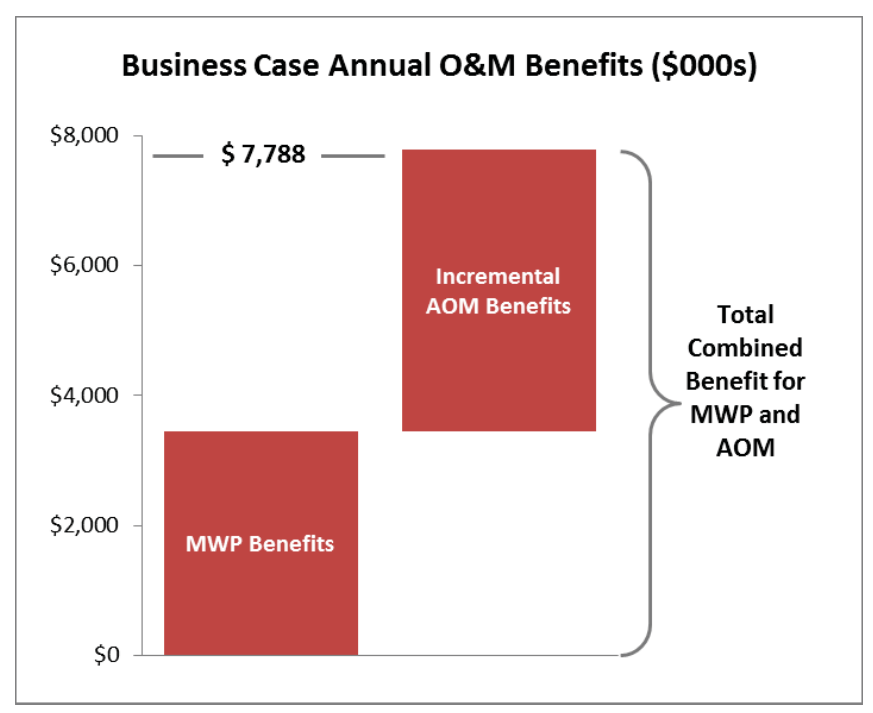

\section{Figure 2: Benefits of MWP and Incremental Benefits of AOM}

While the business case developed for MWP focused on labor savings that could be achieved in the field with use of technology, the business case developed for AOM focuses on field coordination and oversight during an outage. This case presents a suite of technologies, postulates the improvements in outage management capabilities, and quantifies the benefits using the BCM and BCMW to provide the present value of AOM to a typical two-unit plant. The results were verified at an operating plant and are considered to be reasonably accurate, if not conservative. This report, along with the associated workbook, presents a generic business case with a rough order of magnitude that provides directional guidance to NPPs that are interested in developing a similar business case. 


\section{CONTENTS}

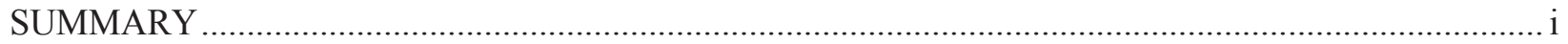

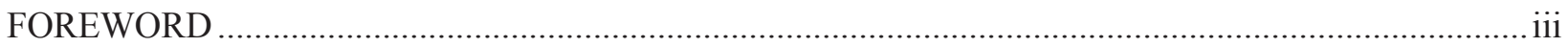

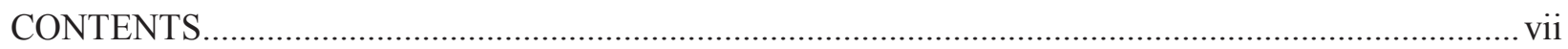

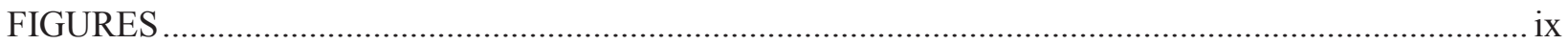

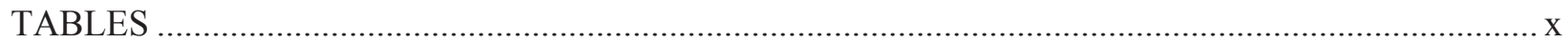

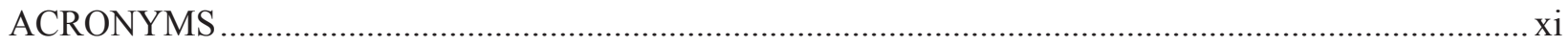

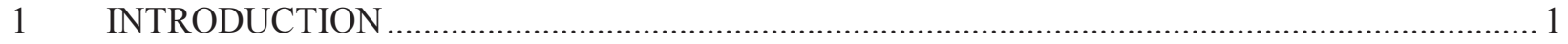

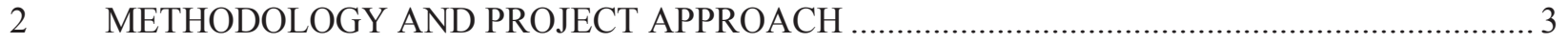

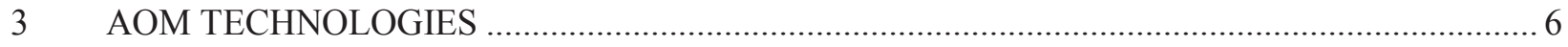

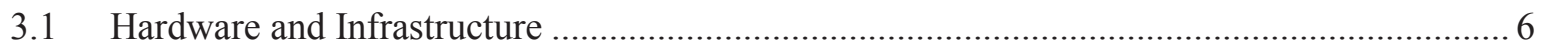

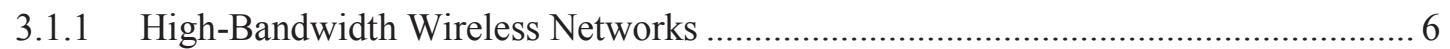

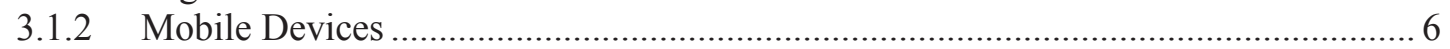

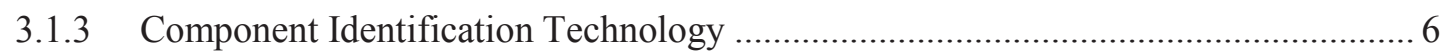

3.1.4 Mobile Wireless Video Cameras .............................................................. 7

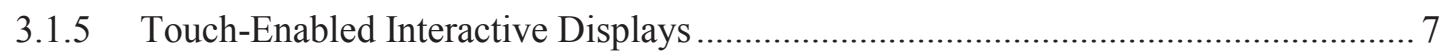

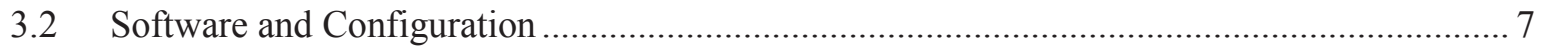

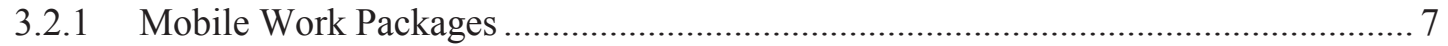

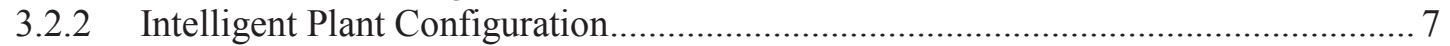

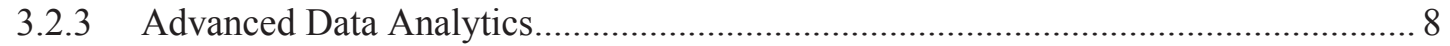

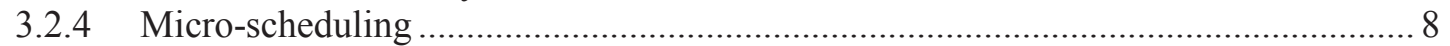

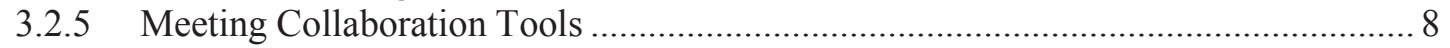

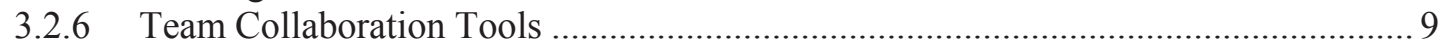

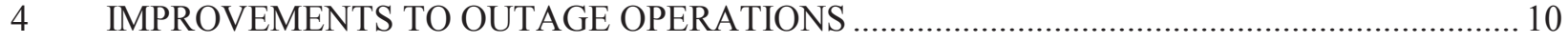

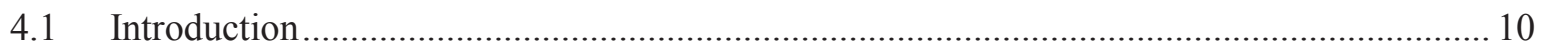

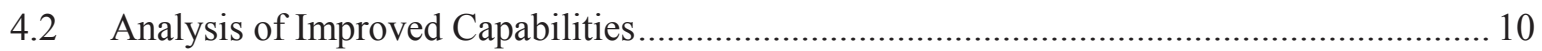

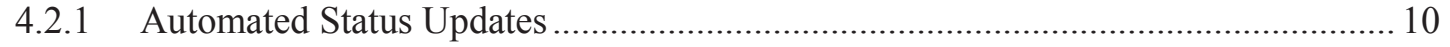

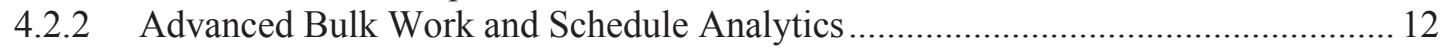

4.2.3 Networked Meetings (Remote Access) ..................................................................... 14

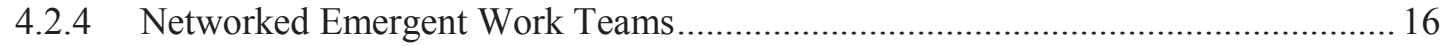

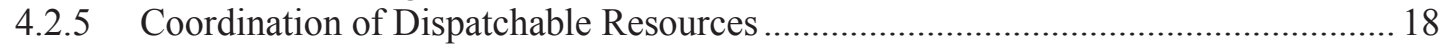

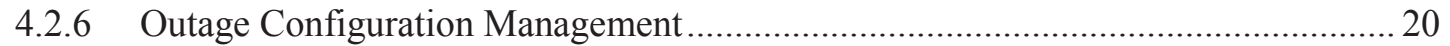

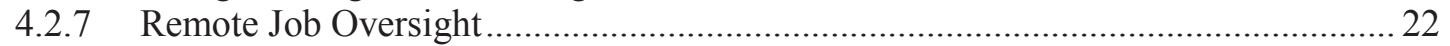

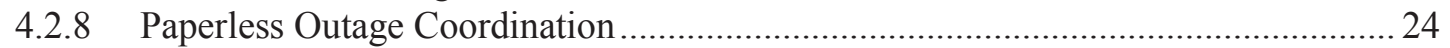

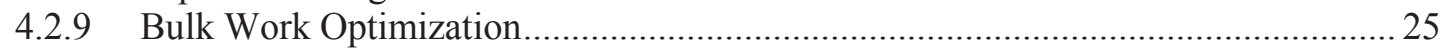

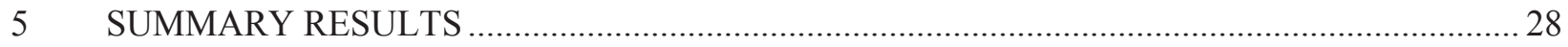

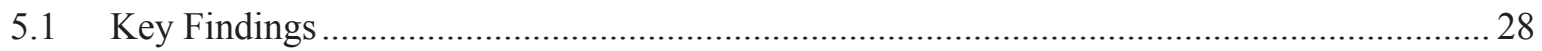




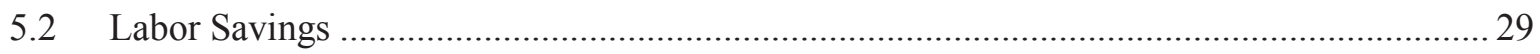

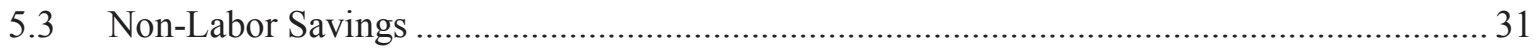

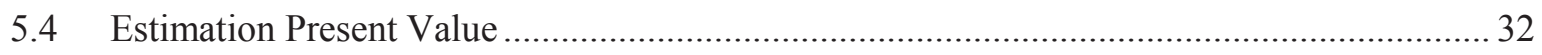

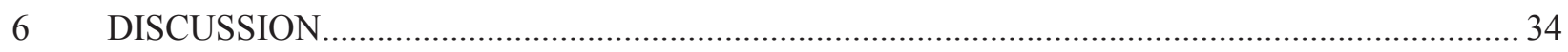

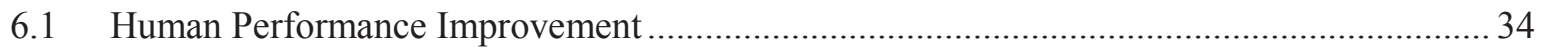

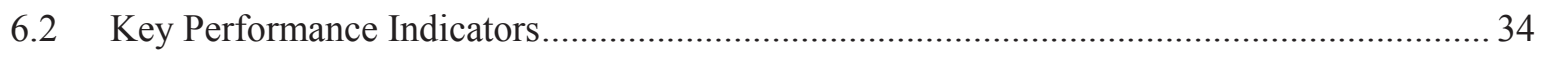

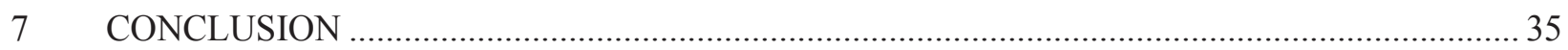

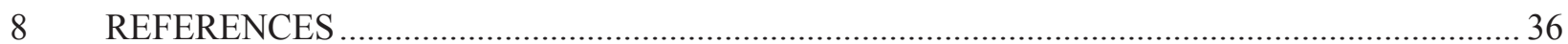




\section{FIGURES}

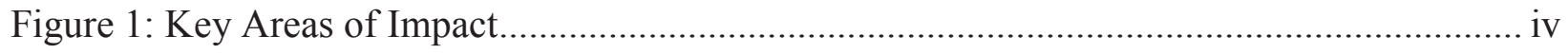

Figure 2: Benefits of MWP and Incremental Benefits of AOM .......................................... vi

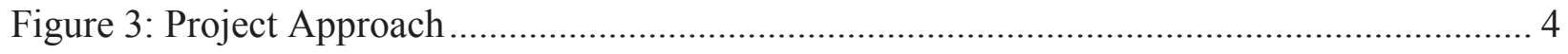

Figure 4: Sample Row from Opportunity Worksheet ........................................................... 5

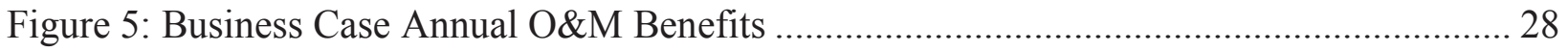

Figure 6: Business Case Annual Labor and Non-Labor Savings .......................................... 29

Figure 7: MWP and AOM Combined Harvestable Annual Labor Savings............................... 30

Figure 8: AOM Incremental Harvestable Annual Labor Savings ........................................... 31

Figure 9: Non-Labor Savings in Relation to Labor Savings................................................. 32 


\section{TABLES}

Table 1: List of NPP Personnel Interviewed during BCM Validation ........................................ 5

Table 2: Annual Benefit and Present Value of MWP and AOM Business Cases ...................... 33 


\section{ACRONYMS}

$\begin{array}{ll}\text { AOC } & \text { Advanced Outage Controls } \\ \text { AOCC } & \text { Advanced Outage Control Center } \\ \text { AOM } & \text { Advanced Outage Management } \\ \text { BCM } & \text { Business Case Methodology } \\ \text { BCMW } & \text { Business Case Methodology Workbook } \\ \text { BEA } & \text { Battelle Energy Alliance } \\ \text { CBP } & \text { Computer-Based Procedures } \\ \text { CSCW } & \text { Computer Supported Cooperative Work } \\ \text { EPRI } & \text { Electric Power Research Institute } \\ \text { FTE } & \text { Full-Time Equivalent } \\ \text { II\&C } & \text { Instrumentation, Information, and Control } \\ \text { KPI } & \text { Key Performance Indicator } \\ \text { LWR } & \text { Light Water Reactor } \\ \text { LWRS } & \text { Light Water Reactor Sustainability } \\ \text { MWP } & \text { Mobile Work Packages (including CBP) } \\ \text { NPP } & \text { Nuclear Power Plant } \\ \text { NPV } & \text { Net Present Value } \\ \text { OCR } & \text { Optical Character Recognition } \\ \text { O\&M } & \text { Operating and Maintenance } \\ \text { POE } & \text { Power Over Ethernet } \\ \text { QC } & \text { Quality Control } \\ \text { QR } & \text { Quick Response } \\ \text { RFID } & \text { Radio Frequency Identification } \\ \text { R\&D } & \text { Research and Development } \\ \text { WMS } & \text { Work Management System } \\ & \end{array}$




\section{A Business Case for Advanced Outage Management}

\section{INTRODUCTION}

Most nuclear reactors in operation in the U.S. today were commissioned in the 1970s and 1980s, with an average age of approximately 35 years. As the original 40-year operating licenses for many of these plants are expiring, many plants today are seeking relicensing for an additional 20 years and beyond. However, the economic environment for generation has changed since many of the original licenses were issued and many operators are questioning whether there are cost effective alternatives to extending their licenses. Innovation in the energy sector has put competitive pressure on the nuclear industry as costs for alternative fuels have come down dramatically. Fracking technology has brought down to price of natural gas to unprecedented low levels. Twenty-year forward curves offer little promise the gas prices will raise in any significant way in the near or long-term future. Combined cycle plants are relatively cheap to build and have much lower operating costs. Coal plants are converting to natural gas and new pipeline infrastructure is being built out. Moreover, renewable energy costs are coming down year over year and have very low operating costs, as well as government incentives that effectively lower the cost of capital investment.

In contrast, nuclear plant operators are struggling to control rising O\&M costs. While most industries are driven by competitive market forces to innovate and provide value through lower costs, the highly regulated nuclear industry has been driven by an overriding concern for public and environmental safety. As such, operators have developed very conservative risk profiles. When compared to other industries, operators are slow to embrace changes that promise to automate human functions and lower costs. The operator must consider if the change will be in conflict with existing regulations, security requirements, or have other unintended consequences to reliability and safety. Corrective action programs have done little to promote innovation. Instead, they have often added manual steps to processes (e.g., visual inspections and verifications) to address human performance issues. In recent years, the industry has recognized the cumulative effects of decades of reflexive responses to events and regulatory oversight.

So it is no surprise that promising innovations which automate business processes in other industries are often met with skepticism by nuclear plant operators. Modern digital infrastructure is simply not present in nuclear plants today and it is admittedly difficult to modify the plant to accommodate digital innovations when faced with new competitive market forces. However, if we look to more competitive industries, we find many examples of how innovation has been used to transform traditional business models to provide a product or service with both increased economic value and reliability for the end user.

Very recently, the nuclear industry launched a broad initiative, known as The Nuclear Promise, to reduce operating costs by $30 \%$. To date, this has consisted of targeted cost reduction opportunities of a somewhat limited nature, based on good practices that have been formulated on one of the operating companies. It does not involve a comprehensive effort to restructure the business to achieve substantially lower operating costs. And while these cost reduction opportunities are sensible business efficiencies that most plants can implement, it is not clear how they translate to the bottom-line cost of operation. 
One particular area of opportunity to improve plant capacity factors is further reduction in refueling outage durations. Digital technologies can indeed address many of the problems that today make managing outage work and emergent technical issues very difficult. However, the lack of sound business cases that demonstrate how these improvements can actually lower costs and reduce outage lengths has proven to be a sizable barrier in funding such improvements. While it is not difficult to project potential efficiency gains in a given plant work activity, the nuclear operators have not had a proven BCM for projecting the savings across the entire plant organization such that overall operating budgets can be commensurately reduced.

As described in the Foreword of this report, the II\&C Systems Technologies Pathway developed the BCM to help NPP operators evaluate the impacts of new technology on their operations. A study was conducted in 2015 utilizing the BCM to evaluate Mobile Work Package technologies and substantial benefits were demonstrated. This study builds upon this work to demonstrate the scale of benefits that can be achieved by applying technology to outage operations and management.

Outage management consists largely in gathering and analyzing information from field work activities. For most plants, communications are manual in nature and are subject to several handoffs. In the time it takes for an outage control center to receive, process and report information, it no longer up-to-date. This study looks at technologies that improve the communication of information and provide analytical support, which in turn forms a better basis and earlier response in decision making. With adoption of current and emerging technologies, information flow will be faster, data will be available when needed, and decisions will be guided by predictive analysis. As a result, the outage organization will require fewer resources (i.e., augmented and temporary staff), and will be able to manage the work better so that the likelihood of schedule overruns are greatly reduced.

The business case is presented as a generic representation of the potential savings, meaning that it provides a rough order of magnitude of benefit and directional guidance to NPP operators that are interested in developing a similar business case. The savings were derived from information obtained from a leading, two-unit nuclear plant with an exceptional operating record. The information consisted of actual outage management reports, outage work activity schedules, and related performance assessments, as well as interviews of managers and outage work coordinators across the organization. The efficiency factors assumed in this business case were validated in these interviews. It should be noted that the efficiency factors derived for use in this report have been rounded in a conservative direction so as to protect the proprietary information of this nuclear plant. 


\section{METHODOLOGY AND PROJECT APPROACH}

The BCM provides a structured guide to utilities for building a business case for adopting emerging digital technologies in a manner that captures the total organizational benefits that can be derived from the improved work methods. This includes direct benefits to the targeted work processes, efficiencies gained in related work processes, and avoided costs through the improvement of work quality and reduction of human error.

In addition, the BCM identifies the NPP work processes to employ the Business Case Methodology Workbook (BCMW) for benefits/cost savings identification. This approach enables collaboration between the II\&C Pathway and utility partners in applying new technologies across multiple NPP organizations and their respective work activities, wherever there is opportunity to derive benefit. In this manner, the BCM drives an "economy of scale" that maximizes the value of the technologies relative to the implementation cost.

The BCM leverages the fact that, in spite of what seems to be a wide and disparate array of work activities among an NPP's operational and support organizations, the work activities themselves are largely composed of common tasks. For example, whether the work activities are in Maintenance, Operations, Chemistry, Radiation Protection, or even Security, they are largely composed of such common tasks as pre-job briefs, use of procedures, correct component identification, emergent conditions requiring work package alteration, etc. It is at this task level that the technologies are applied, and therefore the benefits of the technologies can be realized across as many plant activities as can be identified to employ these common tasks. As a result, a much more comprehensive business case can be derived with a commensurate increase in the benefit/cost ratio. This has the added benefit of driving consistency in work methods across the NPP organizations, a fundamental principle of successful NPP safety and operational management.

The business case for Advanced Outage Management (AOM) is built upon a prior pilot project technology business case for Mobile Work Packages (MWP). During that study, data were collected from a participating NPP to evaluate the benefits of electronic work packages and Computer-Based Procedures (CBP) on general field operations, both on-line and during outages. Field observations and time trials were conducted to evaluate potential savings, and work overall field work was quantified by collecting data from the plant's work management system and other sources. The study made assumptions around availability of technology to support MWP, which included plant wide broadband wireless communications and personal devices (i.e., tablets), that would allow workers to follow CBP and communicate with maintenance supervision, work management, operations and other crews as required. The collected data was then analyzed and fed into the BCMW to evaluate the potential annual benefit to the plant.

The BCM for AOM uses the MWP study as the underlying basis for outage management improvement, in that it is largely dependent on automated field activities that can exchange outage data in real-time. In other words, this study assumes that the technologies to support MWP are already implemented and associated savings have already been achieved. The evaluation of benefits for AOM is therefore incremental to those of MWP. While the business case for MWP was primarily focused on benefits for field work activities, the case for AOM focuses on the benefits to outage management, supervision and 
support organizations as a result of advanced technologies. In some cases, the technologies will have already been provided as part of implementation of MWP, and in other cases, AOM will require incremental improvements to current technologies, or the application of new technologies. The full suite of required technologies is described greater detail in the next section of this report.

Because much of the analysis required for the AOM business case had already been collected and the business case for a large portion of the combined study had already been produced, the approach for this study focused less on data collection and on-site analysis. Instead, the opportunities presented by technologies for AOM were initially evaluated by industry experts off-site using the BCMW and estimates were made supported by site data received from a participating NPP (e.g., outage duration, work activity curves, etc.). The calculated benefits using the BCMW were then presented to and validated by participating NPP management representing a broad range of outage functions. An overview of the approach used for this BCM is outlined below.

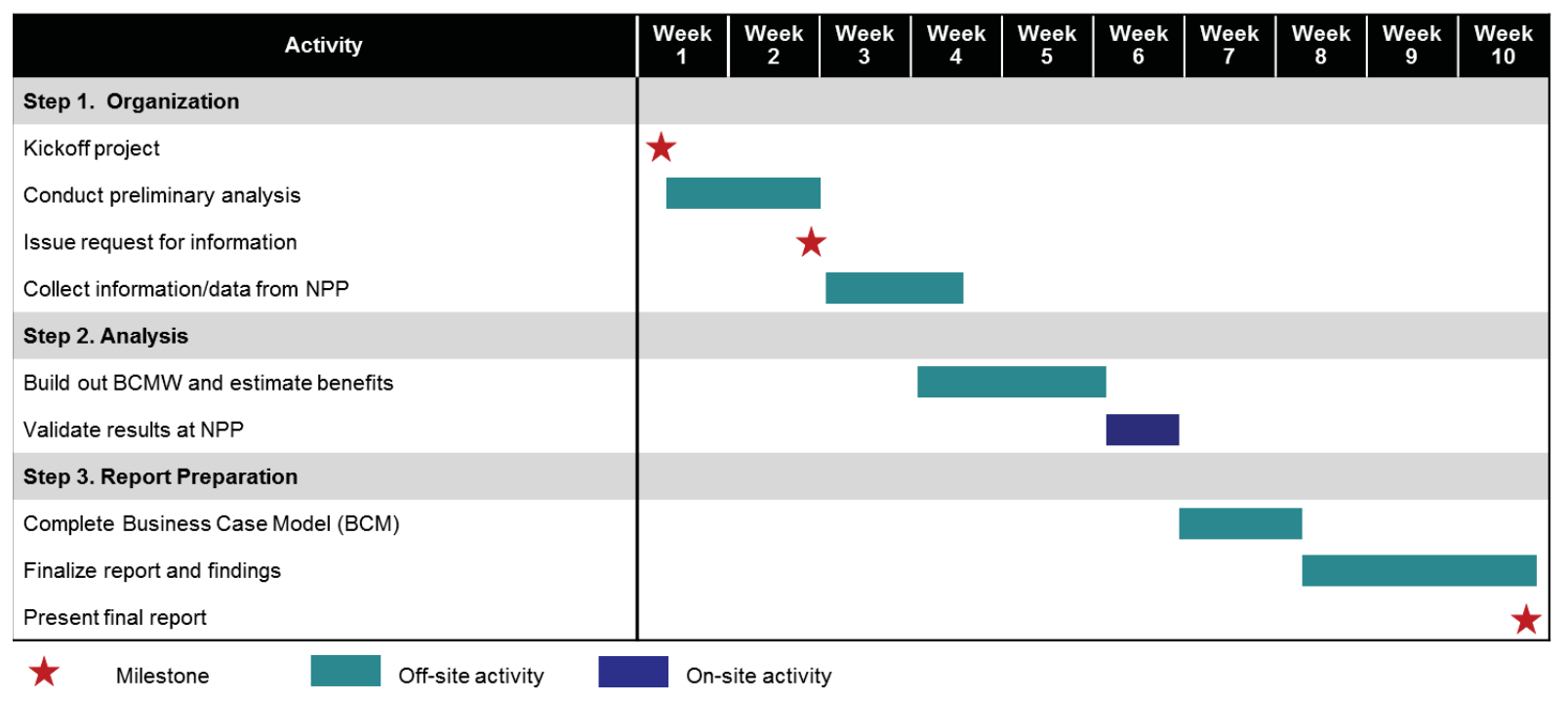

Figure 3: Project Approach

To assist the off-site analysis and validation by partner utility outage management staff, an Opportunity Worksheet was developed and incorporated into the BCMW. This worksheet walked the evaluating team through the analysis of benefits by first asking the team to identify the improved capability (i.e.

opportunity) that is enabled by technology. To view opportunities in terms of new capabilities proved to be helpful as many capabilities are enabled by application of a suite of technologies rather than a single "magic bullet". By following this worksheet, the team was able to identify the overall benefits and the outage functions that are impacted by the improved capability. The team then decided how the benefit might be quantified and a calculation was recorded. This helped the team understand if any additional data needed to be collected to support the calculation used. Finally, the calculation was entered into the BCMW worksheets to produce a quantifiable benefit for each task impacted in terms of labor and nonlabor savings. A sample of the Opportunity Worksheet is presented in Figure 4 below. The completed Opportunity Worksheet developed for this business case is provided in Appendix A. 


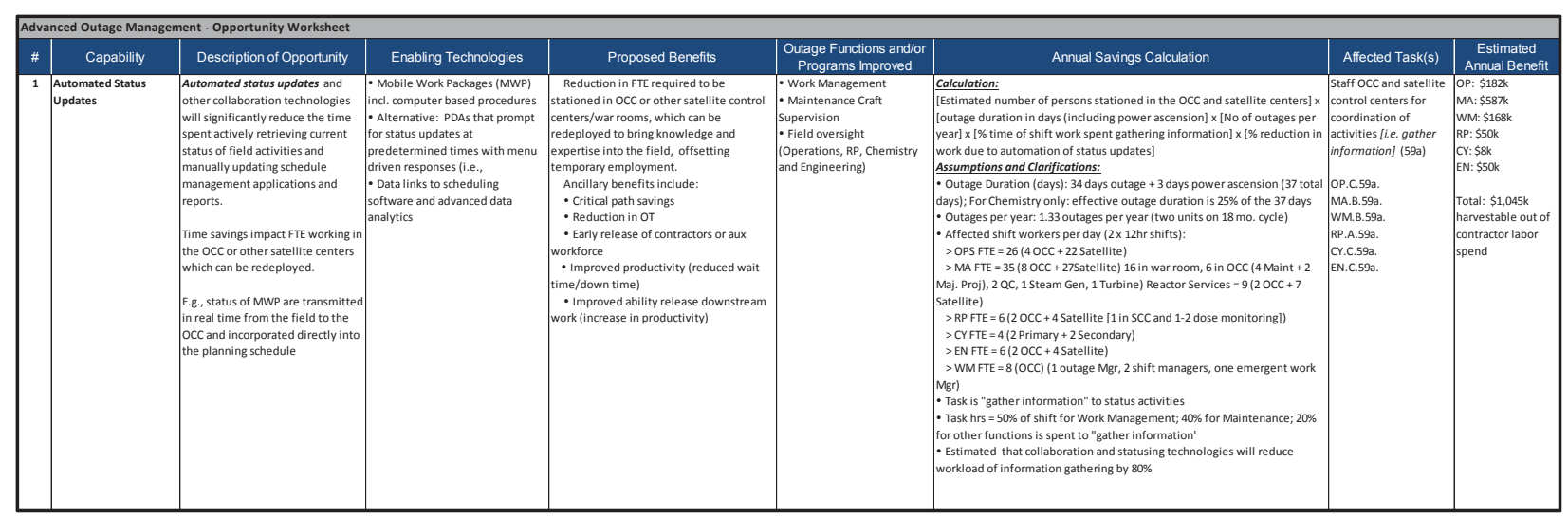

Figure 4: Sample Row from Opportunity Worksheet

Once the Opportunity Worksheet and the BCMW were completed, the results were validated through a series of interviews with plant personnel at a partner nuclear plant. A list of personnel interviewed is provided in the table below. During each interview, the team walked through the Opportunity Worksheet to confirm assumptions made for number of people impacted by the opportunity, and the estimated efficiencies proposed. The worksheet and associated tasks on the BCMW were adjusted accordingly. In all cases, NPP personnel expressed that the results, in their experience, were directionally correct and reasonably accurate, if not conservative.

Table 1: List of NPP Personnel Interviewed during BCM Validation

\begin{tabular}{|l|l|}
\hline \multicolumn{2}{|l|}{ NPP Personnel Interviewed During Validation of the AOM BCM } \\
\hline Work Management Manager & Maintenance Manager - Valves \& Civil \\
\hline Outage Manager & Maintenance Manager - Electrical/I\&C \\
\hline Shift Outage Manager & Fleet Reactor Services Manager \\
\hline Shift Outage Manager \& Design Engineering Director & Steam Generator Services Manager \\
\hline Shift Outage Manager \& Engineering Director & Plant Modification Supervisor \\
\hline Work Management Manager & Turbine Services Manager \\
\hline Operations Supervisor & Reactor Engineering Supervisor \\
\hline Operations Shift Manager (2) & Radiation Protection Manager \\
\hline Chemistry Supervisor (2) & Radiation Protection Supervisor \\
\hline Performance Improvement Manager & \\
\hline
\end{tabular}




\section{AOM TECHNOLOGIES}

The following section contains brief descriptions of the AOM technologies that are credited in the Opportunity Worksheet. They are presented in two categories: 1) Hardware and Infrastructure and 2) Software and Configuration.

\subsection{Hardware and Infrastructure}

\subsubsection{High-Bandwidth Wireless Networks}

Many of the advanced outage functions and improved capabilities described in Section 4 require connectivity via wireless networks [3]. Plant wide wireless networks will enable connection of mobile workers to the Outage Control Center (OCC), allow real-time status updates from MWPs, allow the use of streaming wireless video feeds, and support internet communication options. Plant wide wireless networks have numerous applications outside of outage management, and plants are not likely to install plant wide wireless networks just for outage management. However, some NPPs install temporary wireless networks in containment and other strategic locations during refueling outages. Several domestic NPPs have installed or have current projects to install plant wide wireless capability. Lower frequency broadband communications technologies such as 4G LTE and WiMAX have promising potential to offer secure broadband communications that can penetrate containment, thus eliminating the need for temporary modifications during an outage to establish communications inside containment during an outage. For technical information regarding wireless network installation in a NPP, refer to Electric Power Research Institute's (EPRI) Implementation Guideline for Wireless Networks and Wireless Equipment Condition Monitoring [4].

\subsubsection{Mobile Devices}

Mobile worker devices include any number of hand-held electronic devices that provide information to and allow interaction with field workers [5]. In the AOM concept, mobile worker devices will support MWPs as well as providing voice and video communication capability. A number of form factors are available depending on the specific end users need, but typically a mid-sized tablet computer with an embedded camera and wireless network capability is sufficient. The digital cameras that are typically included in the hand-held field devices can be used for a variety of purposes, including recording still pictures or video of the job site, work conditions, or emergent problems. They can be used to identify components in conjunction with applications to read bar codes, QR codes, or even characters with optical character recognition (OCR) technology. Various rugged devices are an option or rugged cases may be used to protect consumer models.

\subsubsection{Component Identification Technology}

There are a variety of technologies that can be used for automated component identification, including bar codes, QR codes, optical character recognition, and near-field technologies such as radio frequency identification (RFID). These technologies can be placed on or embedded in component identification tags that are tethered to the components themselves. The field workers can use identification technologies on board the hand-held field devices to query the component identification tags to ensure that they are 
working on the correct component as specified in their mobile work package. This could involve the use of the digital camera in the field device or an RFID receiver.

\subsubsection{Mobile Wireless Video Cameras}

High-quality video images are an effective form of communication [5]. Real-time video feeds of an issue or ongoing work can convey much more information than a static picture or voice report. Remote video cameras are currently used in several areas during NPP outages. Currently, these cameras are used to monitor outage progress in containment, on the refueling floor, and in the turbine building. These cameras are typically power-over-ethernet (POE) type cameras that are set up at the beginning of the outage and remain in place for the duration of the outage. If a wireless network is available, wireless-enabled cameras can be used to provide temporary activity monitoring in locations not observable by the POE cameras typically installed. In addition, battery packs could be used to provide completely wireless video monitoring capability. Another option is to use hard hat mounted video cameras to stream a video signal to the OCC or other satellite center to provide direct viewing of work-in-progress or job conditions.

\subsubsection{Touch-Enabled Interactive Displays}

Use of large format touch-enabled interactive displays (60" to 80") can be used to support team collaboration both face-to-face and remotely [5]. Touch screens are usually combined with one of the collaboration software packages. To fully support remote collaboration, webcams and microphones can be added as well. In an Advanced Outage Control Center (AOCC), multiple large screen monitors can be used to display information. Use of collaboration software allows information displayed in the OCC to be viewed and updated from any location, improving the site's collective situational awareness while minimizing low-value work required maintaining static displays on whiteboards. In addition, these displays may be used to provide visual content to routine briefings and facilitate remote communications.

\subsection{Software and Configuration}

\subsubsection{Mobile Work Packages}

MWP are computerized forms of work instructions, such as CBP and automated work packages (AWP). They have a number of features that improve work efficiency, human performance, and interface with the larger organization. They have an inherent ability to enforce work standards such that common human errors made with paper-based documents are prevented. They automate the execution of tedious functions such as data recording, computations, document place-keeping, etc. They report status and other information automatically and transparently to interfacing organizations, without requiring the attention of the work package performer. These features in aggregate compose a powerful tool to manage the quality and timeliness of plant work activities while keeping the larger organization informed of important information as it happens.

\subsubsection{Intelligent Plant Configuration}

Intelligent Plant Configuration technology uses a variety of information sources about the current or upcoming configuration of the nuclear plant to develop a composite picture of changes and conflicts in the required plant configuration for any point in the outage. These sources could be current or upcoming steps in an authorized procedure or work instruction package. It could include information derived from 
the plant I\&C systems about the actual plant configuration. It could include requirements from the plants Technical Specifications or Defense-in-Depth measures (such as protected train of equipment). It could include information from the Clearance and Tag-Out System. It could include information from special sources such as containment closure requirements or plant security requirements. Again, all of these sources can be combined to determine whether the plant meets (or will meet at some time in the future) configuration requirements for the purposes of nuclear safety, personnel safety, license requirements, or work execution.

\subsubsection{Advanced Data Analytics}

Advanced data analytics is the use of emerging information processing technologies that can derive intelligence from structured and unstructured data sources. Structured data sources are such things as data bases, alarm lists, plant instrumentation signals, etc. Unstructured data sources are such things as video streams, pictures, emails, voice mails, meeting notes, ambient noise, etc. Advanced data analytics approximates the capabilities of humans in being able to process all of these sources and derive meaningful insights or conclusions. This is currently the role of outage managers and coordinators, as they are tasked with being aware of all of these sources of information as they monitor the progress of the outage work and the condition and configuration of the physical plant over the course of an outage. The advantage of advanced data analytics is to be able to do this at computer speed on a 24/7 basis, constantly analyzing all of these sources for actionable intelligence and reporting it to the outage management team. It is expected that this technology can be developed to assist the outage team in specific applications to allow them to spend less time on information gathering and analysis, and more time on problem solving and work direction. Over time, this type of technology is expected to grow in capability and application to the point it could be a substantial offset in human labor required to manage an outage.

\subsubsection{Micro-scheduling}

Micro-scheduling is a term for a new type of capability to provide tactical scheduling of support activities on a very fluid basis as work on outage activities progresses to the point where the support is needed. For example, safety-related components sometimes need Quality Control (QC) inspections of one or more steps in a work procedure, but not for the entire work activity. It is very hard to predict exactly when that support will be needed because the rate of progress in the job is difficult to predict. Today, this coordination is conducted by phone or radio, and leads to inefficiencies since there is always a limited number of the support resources that have to cover a large number of jobs. Micro-scheduling will automatically predict when a support resource will be needed, and also allow the job lead to make manual adjustments to the predicted time directly on a mobile device without relying on two-way communication. This will result in more efficient use of the support resources and less wait time for the crews performing field activities when the support resources are not there when needed.

\subsubsection{Meeting Collaboration Tools}

These tools enable real-time face-to-face communications over networks for remote parties engaged in a particular discussion. They allow sharing of computer screens and interactive development sessions in which the remote parties can interactively share information or sketch solutions together. When combined with other technologies, they enable critical experts to effectively participate in technical discussions 
regardless of their physical location, thereby allowing rapid responses to changing or emerging situations in regard to outage management.

\subsubsection{Team Collaboration Tools}

Collaboration software, also known as groupware, can be an effective tool for outage communication [5]. Collaboration software is one element of a larger topic of Computer Supported Cooperative Work $(\mathrm{CSCW})$. $\mathrm{CSCW}$ combines the understanding of the way people work in groups with the enabling technologies of computer networking, associated hardware, software, services, and techniques. First introduced in 1984, CSCW provides two approaches technology-centric or work-centric viewpoints to support groups of individuals collaborating from different locations. The technology-centric approach emphasizes the design and implementation of computer technology aimed at supporting groups working together, while the work-centric approach is geared at the design and implementation of computer systems supporting group collaboration.

Several collaboration software package options are available to support the AOCC function. Some collaboration software supports real-time collaboration, while others support near real-time collaboration. Typically, real-time collaboration requires more expensive software and near real-time is probably adequate for most applications. A combination of near real-time software for bulk work and specialized real-time capable software for intensive collaborations may be optimal. 


\section{IMPROVEMENTS TO OUTAGE OPERATIONS}

\subsection{Introduction}

The BCM was created to help NPPs evaluate how application of new technologies can benefit plant operations. Evaluating application of technologies individually may demonstrate marginal benefits, but it is not until the suite of available technologies is evaluated holistically can the synergies be understood and the benefits fully described. The BCM allows users to evaluate the impact of multiple technologies across all plant operations. In this study, time was first spent postulating how outages might be conducted utilizing advanced technologies, and where savings could be realized. To organize thoughts, an "Opportunity Worksheet" was created to guide users through a process that identifies improvements to capabilities. These improved capabilities were then examined further quantify benefits using the BCMW workbook. The team identified the following capabilities that would be improved by utilization of the suite of AOM technologies described in the previous section.

\subsection{Analysis of Improved Capabilities}

\subsubsection{Automated Status Updates}

\section{Discussion}

Automated status updates and other collaboration technologies significantly reduce the time spent actively retrieving current status of field activities and manually updating schedule management applications and reports. Time savings translates to reduced full-time equivalents (FTEs) working in the OCC and other satellite centers, which can be redeployed to other outage work. Data links are established to other data intensive software and scheduling platforms that can support analysis. For example, the status of a MWP is transmitted in real time from the field to the OCC and incorporated directly into the planning schedule.

Automated status updates have secondary benefits in addition to the time savings. They occur on a realtime basis as work steps are signed off in the controlling documents (procedures or work instructions). This means that they are timely and objective, representing the actual work progress and not a delayed or optimistic view of the progress. Also, the reporting of work status is not disruptive to the work crew, distracting their attention from critical steps. In turn, this real-time work status can be used in the timely release of successor work activities that are dependent on upstream activity completion. The net effect is more effective schedule management with less effort.

\section{Enabling Technology(s)}

The following technology enables automated status updates:

- High-bandwidth wireless networks

- Mobile devices

- Component identification technology

- Mobile wireless video cameras

- $\mathrm{CBP} /$ automated work packages 


\section{Outage Functions or Programs Impacted}

- Outage management

- Maintenance Craft Supervision

- Field oversight (Operations, RP, Chemistry and Engineering)

\section{Calculation of Annual Benefits}

[Estimated number of persons stationed in the OCC and satellite centers] $x$ [outage duration in days (including power ascension)] $x$ [number of outages per year] $x$ [\% time of shift work spent gathering information] $x$ [\% reduction in work due to automation of status updates]

\section{Assumptions and Clarifications}

- Outage duration (days): 34 days outage +3 days power ascension (37 total days); For calculation of benefit in Chemistry only: effective outage duration is $25 \%$ of outage

- Outages per year: 1.33 outages per year based on two units on 18-month cycle

- Affected shift workers per day based on 2 x $12 \mathrm{hr}$ shifts:

$\circ \quad$ Operations $=26(4$ OCC +22 Satellite $)$

- Maintenance $=35(8$ OCC +27 Satellite $) 16$ in war room, 6 in OCC (4 Maint +2 Maj. Proj), 2 QC, 1 Steam Gen, 1 Turbine $)$ Reactor Services $=9$ (2 OCC +7 Satellite $)$

- $\mathrm{RP}=6(2 \mathrm{OCC}+4$ Satellite $[1$ in SCC and 1-2 dose monitoring] $)$

$\circ$ Chemistry $=4$ (2 Primary +2 Secondary $)$

$\circ \quad$ Engineering $=6(2$ OCC +4 Satellite $)$

$\circ \quad$ Outage management $=8($ OCC $)(1$ outage manager, 2 shift managers, 1 emergent work manager)

- Affected task is to "gather information" for statusing activities on schedule

- $\quad$ Task hrs $=50 \%$ of shift hours for Outage management; $40 \%$ of shift hours for Maintenance; $20 \%$ of shift hours for other affected functions

- Estimated that automation of status updates will reduce workload of information gathering by $80 \%$

\section{Estimate of Benefits}

Annual Labor Savings:

Operations: \$182 thousand

Maintenance: \$587 thousand

Outage management: \$168 thousand 


\author{
RP: $\$ 50$ thousand \\ Chemistry: $\$ 8$ thousand \\ Engineering: $\$ 50$ thousand \\ Estimated Total Annual Benefit $=\$ 1.0$ million \\ Estimated Present Value of Benefit $=\$ 6.6$ million
}

\title{
4.2.2 Advanced Bulk Work and Schedule Analytics
}

\section{Discussion}

Outage managers and coordinators spend a significant amount of their time analyzing the vast amount of data that comes into the OCC and other control centers on a continuous basis. Much of the data is confirmation that the outage is proceeding as planned. However, a significant number of work activities have some deviation to their schedules or their scope (such as unanticipated support needs). These deviations must be promptly triaged into 1) items that the work crews or their organizations can handle for themselves, 2) those needing facilitation by the outage management team to avoid overall outage impact, and 3) those whose overall outage schedule impact cannot be avoided (but still need to be addressed). The second case is where quick response by the outage organization can avoid or limit the impact to the overall outage objectives, particularly the schedule.

The problem is that some of these issues are very subtle and hard to identify. An example would be where a critical electrical connection uses a type of potting material that requires a curing time before it can be considered reliable, thereby extending what should have been a quick job into a lengthy delay. If this activity had been given priority 24 hours earlier, the delay would have been avoided. Experienced outage workers can often identify these types of problems based on past experience. Still, many such problems are not recognized until it is too late to recover. In these cases, hindsight often shows where certain "dots could have been connected" to have recognized how resources should have been better deployed to avoid a delay.

Emerging analytical software will enable a new level of data analysis that will more thoroughly detect schedule problems and resource conflicts much as humans are able to do. In the example above, it is likely that the curing time for the potting material would be noted in the electrical connection procedure, and could have been "read" and understood by the analytical software.

Advanced analytics will provide the following benefits:

- Reduced time in schedule analysis and reprioritization of work tasks

- Reduced risk of outage extension

- Improved planning to address extensions if notified earlier - smart extension and release of contractors 
- Improved levelization of deployable resources by support organizations - reduced OT

- Increased bulk work productivity

\section{Enabling Technology(s)}

The following technologies enable advanced bulk work and schedule analytics:

- Advanced data analytics

- Intelligent plant configuration data

- Micro-scheduling

\section{Outage Functions or Programs Impacted}

- Outage management (i.e., schedule analysis)

- Support organizations represented in OCC and satellite CCs

\section{Calculation of Annual Benefits}

[Estimated number of persons stationed in the OCC and satellite centers] $x$ [outage duration in days (including power ascension] $x$ [number of outages per year] $x$ [\% time of shift work spent analyzing information] $x$ [\% reduction in work due to use of advanced data analytics]

\section{Assumptions and Clarifications}

- Outage duration (days): 34 days outage +3 days power ascension (37 total days); For calculation of benefit in Chemistry only: effective outage duration is $25 \%$ of outage

- Outages per year: 1.33 outages per year based on two units on 18-month cycle

- Affected shift workers per day based on 2 x $12 \mathrm{hr}$ shifts:

O Operations $=26(4$ OCC +22 Satellite $)$

- Maintenance $=35(8 \mathrm{OCC}+27$ Satellite $) 16$ in war room, 6 in OCC (4 Maint +2 Maj. Proj), 2 QC, 1 Steam Gen, 1 Turbine), Reactor Services $=9$ (2 OCC + 7 Satellite)

$\circ \mathrm{RP}=6(2 \mathrm{OCC}+4$ Satellite $[1$ in SCC and 1-2 dose monitoring $])$

○ Chemistry $=4$ (2 Primary +2 Secondary)

$\circ \quad$ Engineering $=6(2 \mathrm{OCC}+4$ Satellite $)$

$\circ$ Outage management $=8(\mathrm{OCC})(1$ outage manager, 2 shift managers, 1 emergent work manager)

- Task is "analyze information" to support decisions and deploy workforce in field

- Task hrs $=30 \%$ of shift for affected functions is spent to "analyze information"

- Estimated that advanced data analytics technology will reduce workload of analysis by $40 \%$ 


\title{
Estimate of Benefits
}

\author{
Annual Labor Savings: \\ Operations: \$136 thousand \\ Maintenance: \$220 thousand \\ Outage management: $\$ 50$ thousand \\ RP: $\$ 38$ thousand \\ Chemistry: \$6 thousand \\ Engineering: \$38 thousand \\ Estimated Total Annual Benefit $=\$ 448$ thousand \\ Estimated Present Value of Benefit $=\$ 3.1$ million
}

\subsubsection{Networked Meetings (Remote Access)}

\section{Discussion}

One significant challenge in outage management is keeping a very large number of managers and workers informed of work status, changing conditions, and emergent items. This is accomplished by a standard set of outage meetings (each with a particular focus) as well as special called meetings as needed. Each organization is expected to be represented to both report on their work activities and to take back status information to their workers. Sometimes they participate in group problem solving when a coordinated plan is needed.

While this approach generally works well, it is very time-consuming for the participants. They have the travel time to get to the meetings, the meeting time itself, and often are delayed in leaving due to lowvalue side bar conversations following the meetings. The actual meeting time for many participants consists of listening to many topics that are not relevant to their own work, further decreasing the time efficiency.

Network meetings supported by high-bandwidth wireless networks which display customizable dashboards with real-time status will improve communications and reduce the need for personnel to be physically present in the OCC or other satellite control centers for general status updates and coordination of routine issues. Much of the status information that is presented in an outage meeting could be posted on a dashboard on a real-time basis, with alerts going out to allow groups to access this information directly and not have to rely on meeting representatives to relay it. The meetings themselves can therefore be shorter, and attended by those physically present and those who are participating remotely. Two-way video streaming can enable remote participants to appear on large screens when they need to speak, 
approximating a face-to-face conversation. Those who desire to attend outage meetings when they are not scheduled to work can do so conveniently from wherever they happen to be.

This technology, along with others, can enable an evolving paradigm shift in how a large and fluid organization stays synchronized in time-critical work with safety implications. Some of these concepts have become well-established in social media applications, proving that large numbers of geographically dispersed people can coordinate their status and activities minute-by-minute. Networked meetings and use of dashboards can reduce time burdens on critical resources while actually improving the accuracy and timeliness of outage information dissemination.

Proposed benefits include:

- Reduction in travel time to attend meetings

- Reduction in personnel posted in meetings

- Fewer distractions in the OCC \& Satellite Centers

- Real-time and plant-wide dissemination of information (elimination of information hand-offs)

- Ancillary benefits in time savings to misc. crews, Security personnel, Sr. Mgrs, administration personnel who also attend outage meetings

\section{Enabling Technology(s)}

The following technologies enable advanced bulk work and schedule analytics:

- High-Bandwidth Wireless Networks

- Advanced Displays

- Mobile devices with ability to display asynchronous status updates through customizable dashboards (including platform and tools to build such dashboards)

\section{Outage Functions or Programs Impacted}

- Outage management

- Craft Supervision and Oversight

- Outage Coordinators (i.e., runners)

- Oversight of deployable support resources (i.e., RP, Ops, Chemistry, Engineering)

\section{Calculation of Annual Benefits}

[Estimated number of persons (in FTE) travelling regularly to the OCC to attend daily coordination meetings] $x$ [outage duration in days (including power ascension] $x$ [number of outages per year] $x$ [reduction in workload (i.e. travel time] 


\title{
Assumptions and Clarifications
}

- Outage duration (days): 34 days outage +3 days power ascension (37 total days); For calculation of benefit in Chemistry only: effective outage duration is $25 \%$ of outage

- Outages per year: 1.33 outages per year based on two units on 18-month cycle

- Estimated number of workers travelling to attend meetings per outage day:

$$
\begin{array}{ll}
\circ & \text { Operations }=6 \\
\circ & \text { Maintenance }=16 \\
\circ & \mathrm{RP}=1 \\
\circ & \text { Chemistry }=1 \\
\circ & \text { Engineering }=6
\end{array}
$$

- Reduction in workload $=$ [Estimated travel time per shift $/ 12 \mathrm{hr}$ shift $]$ x $100 \%$

$$
\begin{aligned}
& \text { ○ } 10 \% \text { for RP } \\
& \text { ○ } 20 \% \text { for all other functions considered }
\end{aligned}
$$

\section{Estimate of Benefits}

\author{
Annual Labor Savings: \\ Operations: $\$ 52$ thousand \\ Maintenance: $\$ 168$ thousand \\ RP: $\$ 5$ thousand \\ Chemistry: $\$ 10$ thousand \\ Engineering: \$63 thousand \\ Estimated Total Annual Benefit $=\$ 298$ thousand \\ Estimated Present Value of Benefit $=\$ 1.9$ million
}

\subsubsection{Networked Emergent Work Teams}

\section{Discussion}

Similar to the capabilities described in Networked Meetings, Emergent Work Teams are often formed during outages to quickly dispose of newly discovered issues that threaten the success of the outage in one manner or another. These can be nuclear safety challenges, personnel safety challenges, equipment 
failure issues, work quality issues, and the like. Any of these can also be schedule challenges if they are not resolved in a timely manner.

There is usually a standing process that sets the threshold for forming an Emergent Work Team and specifying expectations for the team, such as composition, methodologies (such as failure investigation processes, fault trees, etc.), authority, reporting, and schedules. These teams usually rely on regular meetings to make investigation plans, coordinate activities, request resources, analyze intermediate results, and report progress. Information is exchanged among the team members in a variety of means and formats. The meetings themselves are relied upon as the periodic points in time when the activities of the team are resynchronized to reflect new knowledge and resulting decisions.

Today, there is a new set of real-time collaboration tools that allow disperse parties to effectively pool their knowledge and coordinate their activities as work activities transpire. And this information sharing can consist of forms of information sharing that are much more effective than data and note sharing such as face-to-face conversations, photos and videos of problems, data sets and graphs taken in test activities, reference documents, turn-over logs, etc. The effect is to allow a diverse team to proceed to a solution much more rapidly than with conventional means using a rigid meeting structure.

Networked Emergent Work Teams supported by collaboration tools_such as OneNote have been demonstrated to greatly reduce emergent issue resolution time. Benefits include avoided impact on critical path schedule and reduced risk of outage schedule overrun due to emergent issues.

\section{Enabling Technology(s)}

- Collaboration tools (e.g., OneNote)

- High-Bandwidth Wireless Network

- Smart Devices (i.e., tablet, PDA)

\section{Outage Functions or Programs Impacted}

Ad-hoc teams assembled to address emergent issues, plan work and re-plan schedule

\section{Calculation of Annual Benefits}

[Estimated number of FTE performing emergent issue analysis and resolution on any given outage day] $x$ [estimated reduction in work hours due to productivity gains] $x$ [outage duration in days (including power ascension)] $x$ [number of outages per year]

\section{Assumptions and Clarifications}

- Outage duration (days): 34 days outage +3 days power ascension (37 total days); For calculation of benefit in Chemistry only: effective outage duration is $25 \%$ of outage

- Outages per year: 1.33 outages per year based on two units on 18-month cycle

- Estimate 10\% savings of FTEs performing emergent issue analysis and resolution throughout outage 
$\circ \quad 2$ FTEs Outage management (1 SOM and 1 emergent work manager)

- 9 FTEs Engineering

- 3 FTEs Maintenance

- 1 FTE Operations (developing execution plans and communicating/coordinating those plans)

○ 1 FTE RP

\title{
Estimate of Benefits
}

\author{
Annual Labor Savings: \\ Operations: $\$ 5$ thousand \\ Maintenance: \$16 thousand \\ Outage management: $\$ 10$ thousand \\ RP: $\$ 5$ thousand \\ Engineering: \$47 thousand \\ Estimated Total Annual Benefit $=\$ 83$ thousand \\ Estimated Present Value of Benefit $=\$ 500$ thousand
}

\subsubsection{Coordination of Dispatchable Resources}

\section{Discussion}

Dispatchable resources for a nuclear outage are those support functions that play a special role in the completion of work activities for line groups. An example would be QC inspectors who have to witness and sign-off that certain job steps were completed in a quality manner. Another example would be field operators who have to lift tags for component testing and then rehang them to allow the maintenance activity to continue. There are a number of other such support functions. What they have in common is two main characteristics:

1. A limited number of these individuals cover a large number of work activities for just the period of time they are needed.

2. There is some uncertainty as to exactly when they will be needed, in that it depends on the progress of the main work activity.

The outage organization uses conventional communication means to approximate when dispatchable resources will be needed for any given job. At a macro level, it is known which jobs on a given day will need various types of dispatchable support. Beyond that, they rely on continuing status updates from the 
job site to estimate the exact time the support will be needed, attempting to optimize conflicting objectives of not holding up the progress of the work activity while not creating unproductive wait time for the dispatchable resource by arriving at the job site too early. For critical path and near-critical path activities, these dispatchable resource are sometimes assigned to a single job, accepting this inefficiency, so there is no delay in this support function. Otherwise, it is a matter of outage cost optimization to have as few of these resources (typically contractor augmentation) as can reasonably cover the work load with an acceptable level of delay in busy periods. Conversations with outage workers confirm that they often experience dead time on work activities due to waiting for dispatchable resources.

The challenge in managing this problem is both the concurrency of the needs, with the progress of various jobs moving independently of each other, along with the bulkiness of the communications, relying of radio and telephone to contact a central dispatcher of the latest estimate of when the resource will be needed.

Micro-scheduling is a term for a collection of technologies that automatically estimate and communicate when support resources will be needed on a given job. In addition, it provides a means for aggregating the needs of the concurrent jobs, examines the relative impact of delays on each of them, and assigns an optimum dispatch scheme for the resources available at the time. Moreover, it does this transparently to the job performers based on the automated statusing capability of their MWP, thereby not distracting their focus on the work quality itself.

Micro-scheduling of work order tasks (along with automated status updates from MWP or similar statusing capability) will allow more efficient assignment of dispatchable resources (i.e., RP, Chem, Ops tagging, etc.). Proposed benefits include reduced wait time for crews, efficiency gains due to timely dispatch of resources which result in lower required staffing levels and overtime required to handle variable work load.

\section{Enabling Technology(s)}

- MWP including CBP

- Micro-scheduling

- Data analytics (for workforce optimization)

\section{Outage Functions or Programs Impacted}

Dispatchable resources from various functions

\section{Calculation of Annual Benefits}

[Estimated number of dispatchable resources] $x$ [estimated reduction in work hours due to productivity gains] $x$ [outage duration in days (including power ascension] $x$ [number of outages per year] 


\section{Assumptions and Clarifications}

- Outage duration (days): 34 days outage +3 days power ascension (37 total days); For calculation of benefit in Chemistry only: effective outage duration is $25 \%$ of outage

- Outages per year: 1.33 outages per year based on two units on 18-month cycle

- Dispatchable resources are $15 \%$ more efficient due to reduction in wait times due to microscheduling

- Estimate number of shift workers affected

○ 10 Operations and Operations Test Group (5 per shift)

○ $\quad 10+20$ augmented FTE Maint QC (total 30)

- 1 Misc. Support Services (e.g., Fueling mobile lifts/cranes, location/digging services, running tools and parts, etc.)

- 20 augmented FTE RP Techs that are dispatchable (not stationed)

○ 5 Security

- Task hrs is based on $12 \mathrm{hr}$ shifts

\section{Estimate of Benefits}

Annual Labor Savings:

Operations: $\$ 66$ thousand

Maintenance: \$157 thousand

Miscellaneous (Maintenance): \$7 thousand

RP: $\$ 85$ thousand

Security: $\$ 23$ thousand

Estimated Total Annual Benefit $=\$ 338$ thousand

Estimated Present Value of Benefit $=\$ 2.1$ million

\subsubsection{Outage Configuration Management}

\section{Discussion}

All outage work must be planned and executed in a manner that maintains plant configuration management requirements for the entire duration of the schedule. This includes the plant Technical Specifications, defense-in-depth measures required by the Maintenance Rule (10 CFR 50.65), license commitments, and other internally imposed requirements. The original outage schedule is developed in accordance with these requirements, and is reviewed by a number of site and off-site nuclear safety oversight groups to ensure compliance. 
Inevitably, the actual schedules of individual work activities shift due to various factors (schedule gains and losses), such that any given job might be presented with different plant configuration conditions than those originally assumed. Therefore, outage managers and coordinators must constantly verify that changes to the schedule still conform to all configuration requirements. This is a very difficult task that relies on a set of process and mandatory reviews by the organization to detect conflicts in this regard. It often becomes a restraining factor on what can be done to reschedule work, or accommodate emergent work, in terms of available work windows that conform to configuration requirements for that particular work activity.

While these processes are generally effective, there is a persistent residual of events in the industry that are not detected beforehand and therefore result in some level of non-compliance. Some of these are serious nuclear safety challenges and result in adverse regulatory actions, such as loss of residual heat removal during periods of reduced reactor coolant water inventory.

As previously stated, avoidance of these types of events rely on review processes conducted by the outage team as well as by nuclear safety oversight organizations. It is labor intensive and requires considerable focus to detect subtle interactions. It is often time-critical because emergent schedule changes have to be resolved quickly to avoid outage performance impacts. In other words, it presents a number of challenges to human performance.

New technologies are emerging that provide much better situational awareness for outage managers. They can integrate diverse sources of plant configuration information, such as the plant I\&C systems, the work packages and procedures that are in use, and real-time plant component status that is supplied by new wireless networks to provide status on components that originally did not have such capability.

Situational awareness informed by intelligent plant configuration software (close coordination of when systems and components are functionally available) will reduce time in degraded safety condition (i.e., detection of prohibited configurations (e.g. tech spec, defence in depth). The primary proposed benefit is a reduction in safety violations (e.g., tech spec violation, work sequencing) and resulting investigation and corrective action follow-up.

The workhour savings for outage management personnel for this capability is already accounted for in the Advanced Bulk Work and Schedule Analytics section above. The savings that are projected in the analysis below represent avoided labor and expenses to resolve a plant configuration management event of some nuclear safety significance. Such an event creates a sizable workload in and of itself, requiring an immediate investigation, a possible halt to outage progress, a possible work stand-down, an apparent or root cause analysis, an extent-of-condition and extent-of cause analysis, a formulation of corrective actions, implementation of corrective actions, oversight reviews by many layers of site and off-site boards, regulatory actions and responses, potentially adverse findings in future Institute of Nuclear Power Operations evaluations, and others.

Given that this is an avoided cost, it is difficult to prove that a postulated event would have otherwise happened. However, over time, the frequency of these types of events that lend themselves to more effective plant configuration control should decrease on a statistical basis. Anecdotal evidence will be found when certain "good catches" result from the use of these tools. 


\section{Enabling Technology(s)}

- Intelligent plant configuration software

- Advanced data analytics

\section{Outage Functions or Programs Impacted}

- Corrective Action Program

- Safety and regulatory margins (defense in depth, maintenance rule, outage incremental core damage frequency)

- Safety System Unavailability

\section{Calculation of Annual Benefits}

[Average number of events per outage] $x$ [\% events avoided] $x$ [estimated time to investigate and analyze and address corrective actions]

\section{Assumptions and Clarifications:}

- 1-2 significant events due to safety violations occur per outage

- Assume 1 avoided event/outage

- Estimated 1,500 man-hrs per event

\section{Estimate of Benefits}

Estimated Total Annual Benefit $=\$ 133$ thousand

Estimated Present Value of Benefit $=\$ 800$ thousand

\subsubsection{Remote Job Oversight}

\section{Discussion}

Effective management and oversight of the bulk work activities in an outage is considerable more difficult than managing the same work during power operations due to the number of contract workers involved in the activities who do not have the same familiarity with the company's work processes and standards. The sheer volume of work requires the appointment of temporary supervisors, some of them contract personnel themselves. The span of control can be quite challenging in that some sites have up to 100 work crews involved in concurrent work activities, with supervisors having multiple crews to manage.

Further complicating this issue is the fact that a foundational nuclear safety principle is that supervisors make frequent trips to the job sites to observe crew work practices, reinforce standards, coach them on undesired behaviors, and gain a first-hand understanding of the work progress and work quality. In 
addition, supervisors are often called to a particular job location to approve deviations from work instructions or procedures, engage in problem solving, authorize additional necessary work tasks, and perform other oversight functions as warranted. All of this is on top of having to attend required outage meetings, react to changing outage schedules, address worker shortages, approve completed work packages, and tend to other supervisory functions.

Technology can play a role in reducing the burden on supervisors without loss of effectiveness through use of remote job oversight capabilities. These include the use of video to observe the job site through any office or portable device (using pan and zoom to direct the camera to the area of interest), face-to-face streaming video discussions with job leads for status and problem solving, direct access to their work instructions and procedures on a real-time basis to assess progress and approve deviations, and ability to access related information such as clearances, test results, etc.

It is recognized that the industry's nuclear safety culture would make limited use of this capability, in that it would not be acceptable to greatly reduce supervisory presence on the job site. However, a blended use of this capability in favorable circumstances would provide greater supervisory effectiveness as well as cost savings. In other words, it could be used to create an even greater supervisory presence (albeit virtual) on the job sites at a greater frequency than possible with physical presence. It could allow a supervisor to check in with second job site when his or her presence is required at a problem job site. Finally, used in a proportionate manner, it could allow a modest reduction in the number of temporary supervisors needed for the outage by increasing their capability in effective span of control.

Wireless Remote Job Oversight (including local video monitoring and other technologies e.g., remote viewing of CBP in progress) will reduce the overall workload for field supervision of activities, including temporary support staff used for work coordination. Proposed benefits include:

- Improved span and control of maintenance supervision and oversight

- More efficient oversight of field work resulting in fewer non-conformances

- Improved productivity of workforce (Hawthorn effect)

\section{Enabling Technology(s)}

- Mobile wireless video cameras

- $\mathrm{CBP}$ (on line viewing of place holder)

\section{Outage Functions or Programs Impacted}

- Field supervision and oversight

- Craft performance

\section{Calculation of Annual Benefits}

[Total number of maintenance supervisors] $x$ [\% of supervisors that can be reduced through increase of span and control of crews] $x$ [number of days of outage] 


\section{Assumptions and Clarifications}

- Assume approx. 100 maintenance supervisors - estimate 5\% can be reduced with improved span and control

- 12 hour shift

- 34 days of outage (roughly covers 1 week of pre-outage offset by early release at end of the outage)

\section{Estimate of Benefits}

Estimated Total Annual Benefit $=\$ 241$ thousand

Estimated Present Value of Benefit $=\$ 1.5$ million

\subsubsection{Paperless Outage Coordination}

\section{Discussion}

There is an enormous amount of paper usage during an outage to supply printed material for the array of outage meetings. One nuclear plant estimates that they use more than 5,000 pages of paper a day just for OCC functions, not counting what is used in other satellite control centers. This also does not account for the cost of ink and supplies, copy equipment purchases/leases/rentals, and personnel time to make these copies. Most of this paper has a very short useful life given the rapid change in outage progress and schedule changes. Meeting attendees pick up a new set of standard reports at each outage meeting, discarding previous sets in recycle containers. Also, given the bulk of paper, it is not feasible to retain old copies of outage reports even when they contain notes items of interest. The sheer volume of paper makes it unwieldly for portable usage and is at best is stacked up in an outage manager's or coordinator's office for later reference if needed.

Paperless Outage Coordination enabled by various AOM technologies including outage control centers equipped with interactive communications (including smart boards and video conferencing capability) and customizable dashboards will eliminate the need to print out schedules, posters, and other handouts. Instead, data will be available live and emulated on various devices when prompted including on personal smart devices. Benefits include reduction in paper use and printer consumables as well as costly maintenance of high-capacity printers and plotters.

\section{Enabling Technology(s)}

- High-bandwidth wireless networks

- Advanced displays

- Mobile devices (i.e., tablet, PDA) that allow asynchronous status updates through customizable dashboards (including platform and tools to build dashboards) 


\section{Outage Functions or Programs Impacted}

- Outage management

- Administrative Support

\section{Calculation of Annual Benefits}

[Estimate of paper per day] $x$ [cost of printing/reproduction per page] $x$ [number of days in outage]

\section{Assumptions and Clarifications}

- Assume 1.6 boxes of paper per day for OCC and satellite centers

- 10 reams of paper per box

- 500 sheets per ream

- 10 cents per sheet O\&M for printing/reproduction

- 37 outage days

\section{Estimate of Benefits}

Estimated Total Annual Benefit (Non-Labor) $=\$ 39$ thousand

Estimated Present Value of Benefit $=\$ 200$ thousand

\subsubsection{Bulk Work Optimization}

\section{Discussion}

There are two main categories of work problems that lead to critical path delays and therefore outage extensions. One case is that of a single system or component problem that cannot be resolved in the available work window before it prevents moving the plant forward in terms of major outage schedule milestones, thereby delaying the start of other critical path work. For example, two redundant trains of Technical Specification-related safety systems are typically required to be operable at a certain point in plant heat-up (e.g. Mode 4 for PWRs). If there were a component problem in just one of these safety system trains, the outage could not progress beyond this point. These types of outage delay concerns are managed through equipment reliability measures and contingency plans for such component failures.

A second category of critical path delays is in bulk work management. The outage schedule is originally laid out on the basis of work items completing on their early finish date as calculated by the scheduling system. However, for most of the work items, there is some margin in their schedule (called schedule float) before they would individually be the cause of a critical path delay.

However, as many of the bulk work items begin to use of their margin, a bow wave of work is created that imposes burdens on the downstream groups that have to absorb the bow wave in a fixed amount of 
time. For example, a valve test group might not get some valve test work items as early in the outage as they were expecting because work on the valves was finishing late (but still within the outage float). As more and more of this happens, then the valve test group could become overwhelmed with work once all of the valves testing became available to work at roughly the same time. So, the pre-outage efforts to levelize the workload for valve test group would be negated and they would be presented with a peak workload challenge that they could not meet.

The new technologies described above in the Advanced Bulk Work and Schedule Analytics section are applicable to this situation, enabling the outage coordinator to do a much more effective job in analyzing the downstream effects of each work item and re-deploying resources to minimize the creation of bow waves that will overwhelm key groups at inopportune times. The time savings afforded by these tools for outage managers and coordinators are accounted for in that section. However, a larger cost impact is attributable to the effect of the delay in major outage milestones, which extends the outage for everyone and keeps a significant portion of the contract workers on site longer than was anticipated. Moreover, the costs for replacement power for the nuclear plant being offline are likewise extended for the duration of the delay. (Note: it is recognized that this cost is dependent on the market structure.)

Bulk work optimization is very difficult with today's technologies and methods, with work command centers resorting to various whiteboard lists of late items and work down curves that examine the raw number of activities completed per day. The shortcoming of workdown curves is that it does little to prioritize the work in a way that ensures a manageable situation for the impacted downstream groups. Better analysis could help avoid the secondary bow waves on downstream groups and provide earlier warning of where additional resources applied to certain jobs would avoid an unmanageable situation as key outage milestone dates are approached.

Modest efficiency gains of $10-15 \%$ in bulk work execution roughly equate to the typical outage extension due to Mode 4 delay resulting in significant savings from timely release of contractors and purchase of replacement power. Additionally, better control of outage duration will directly benefit several KPI.

- Net Generation

- Collective Radiation Exposure

- Unit Capacity Factor

- Unit Capability Factor

- Total Production Cost

- Safety System Unavailability

- Reportable Environmental Events

- $\quad$ Outage Milestones Missed

\section{Enabling Technology(s):}

- High-bandwidth wireless networks

- Mobile devices

- Mobile wireless video cameras

- $\mathrm{CBP} /$ automated work packages

- Advanced data analytics 
- Micro-scheduling

\section{Calculation of Annual Benefits:}

[Number of contractors extended] $x$ [typical extension duration (hrs)] + [cost of replacement power per day] $x$ [average extension]

\section{Assumptions and Clarifications:}

- Assume an average extension to schedule mode 4 of 36 hours

- Assume $30 \%$ of an average of 1,500 contractors per day can be released as scheduled

- Estimate average hourly rate of contractors is \$40 per hour Annual Benefit and Present Value

- Estimate cost of purchased replacement power is $\$ 400,000$ per 24 hours

\section{Estimate of Benefits}

Estimated Non-Labor Savings:

Early contractor release: $\$ 864$ thousand

Replacement power: $\$ 800$ thousand

Estimated Total Annual Benefit $=\$ 1.6$ million

Estimated Present Value of Benefit $=\$ 10.5$ million 


\section{SUMMARY RESULTS}

\subsection{Key Findings}

The overall results provided by the BCM are substantial. The addition of AOM technologies to the MWP Business Case more than doubled the estimated annual savings. The study demonstrates the scale of savings that can be achieved when digital technologies are applied to work processes to the benefit the NPP. Costly manual handoffs of information are reduced, communications are in real time, analysis is supported in real time by analytical tools, and the risk of a costly outage extension is reduced through better management of the bulk work and improved situational awareness. A summary of the annual savings is presented the figure below:

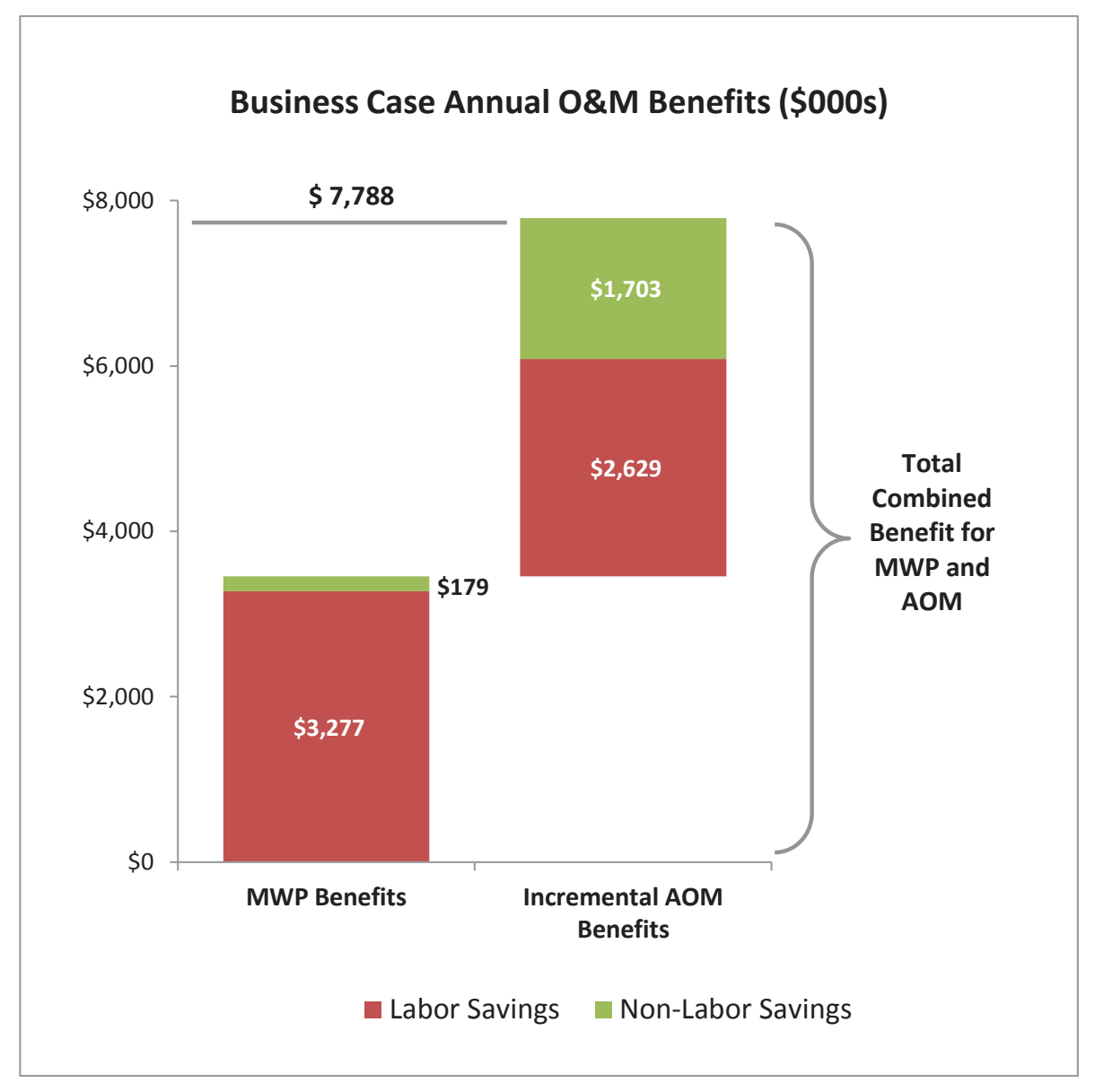

Figure 5: Business Case Annual O\&M Benefits

The combined business case indicates that a typical two-unit plant can save in excess of $\$ 7.7$ million annually in O\&M costs. The figure below provides a breakup of labor and non-labor savings developed in the BCMW. 


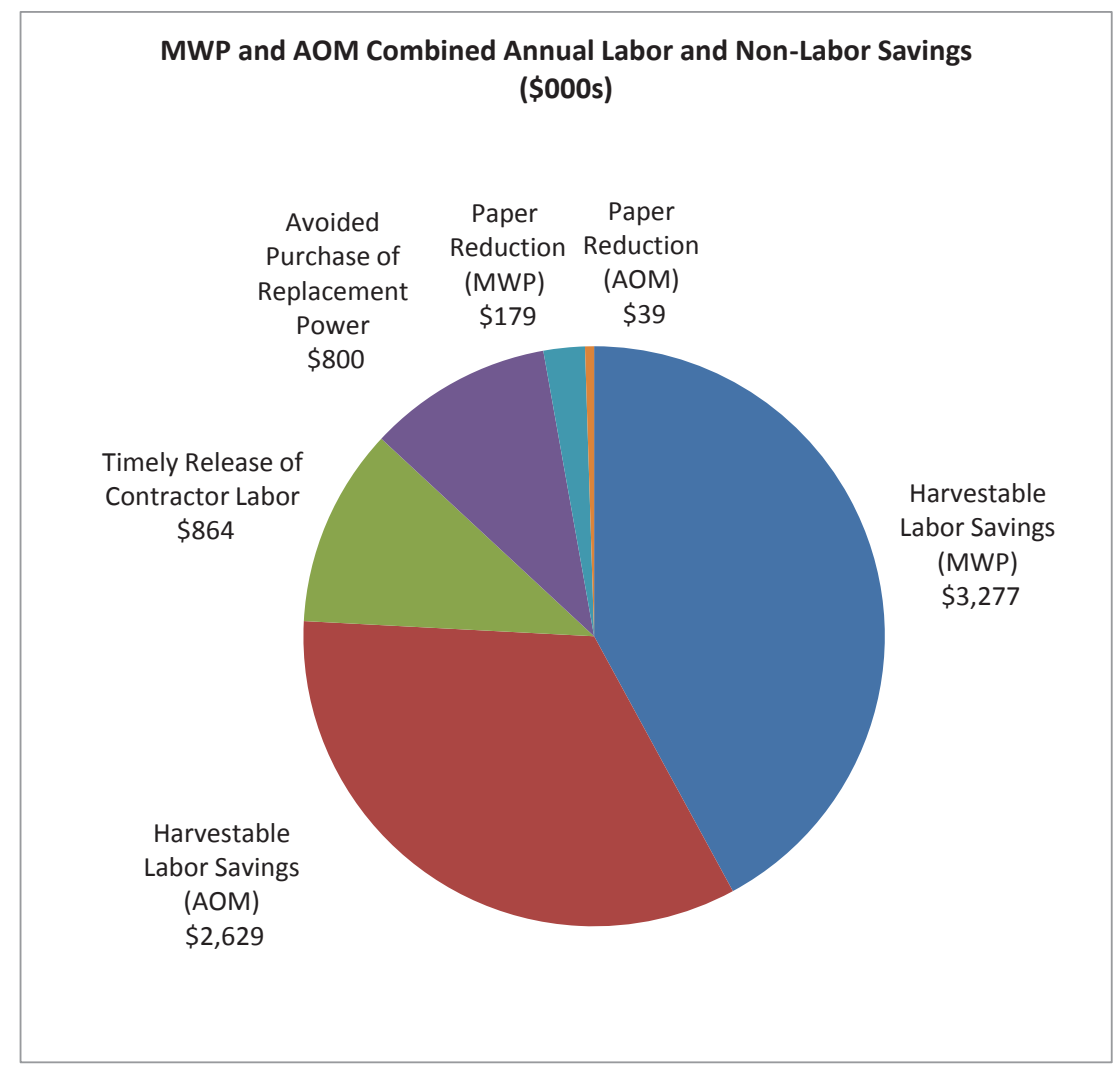

Figure 6: Business Case Annual Labor and Non-Labor Savings

The combined business case indicates that the present value of MWP Business Case and AOM Business Case taken together is in excess of $\$ 48$ million. This tells us that a sizable investment may be considered to adopt a suite of technologies similar to those outlined in this study. While each NPP has a unique set of standards and requirements to analyze investment, the BCM provides a basis by which the estimates made by this team can be challenged at a very granular level.

In all cases in this analysis where metrics were not available as a direct result of observation or data analysis, a conservative estimate was applied and validated with the participating NPP. As such, the figures represented in this BCM represent the lower bound of benefits MWP and AOM technologies. While changes to the inputs would have a linear impact on the outputs, the results reported here are meant to show the lower bound and upside of the BCM as applied to a practical case.

The benefits of MWP have been provided in a prior report and will not be elaborated upon here. However, because the benefits of AOM are largely dependent on the existence of MWP, the results of the combined business case are presented, and the benefits of AOM are presented as incremental to MWP.

\subsection{Labor Savings}

The data collected during development of the Opportunity Worksheet was used to complete the labor portion of the BCMW. In cases where work activities were insufficiently described in the Task Library, new tasks were defined in order to clearly indicate where labor savings are attributable to AOM 
technologies as opposed to those already attributed to the MWP case. The BCMW was used to convert efficiencies in terms of labor hours into dollar savings.

All labor savings identified and attributed to AOM were considered harvestable. Harvestability is defined as the fraction of cost savings that can be taken as a budget reduction. When examining on line labor, labor savings are only considered harvestable if it results in a reduction in work force. However, because AOM applies to outage work, it is assumed that all work force reductions would be accomplished through reduction of contracted labor, augmented staff and overtime. As such, 100\% of labor savings attributable to $\mathrm{AOM}$ is harvestable even though no reduction to the standard organization is envisioned. Moreover, there is an ancillary benefit of allowing staff to move out from the control centers and into the field where their expertise and the power of observation can influence work performance in a positive way.

The BCMW was used to process the efficiencies introduced by AOM to yield annual labor savings of $\$ 2.63$ million in addition to the $\$ 3.28$ million in harvestable annual labor savings from MWP for a combined total of $\$ 5.1$ million. A summary of the labor savings by functional area for the combined business case is illustrated in Figure 7, while the incremental summary of labor savings by functional area for AOM is provided in Figure 8.

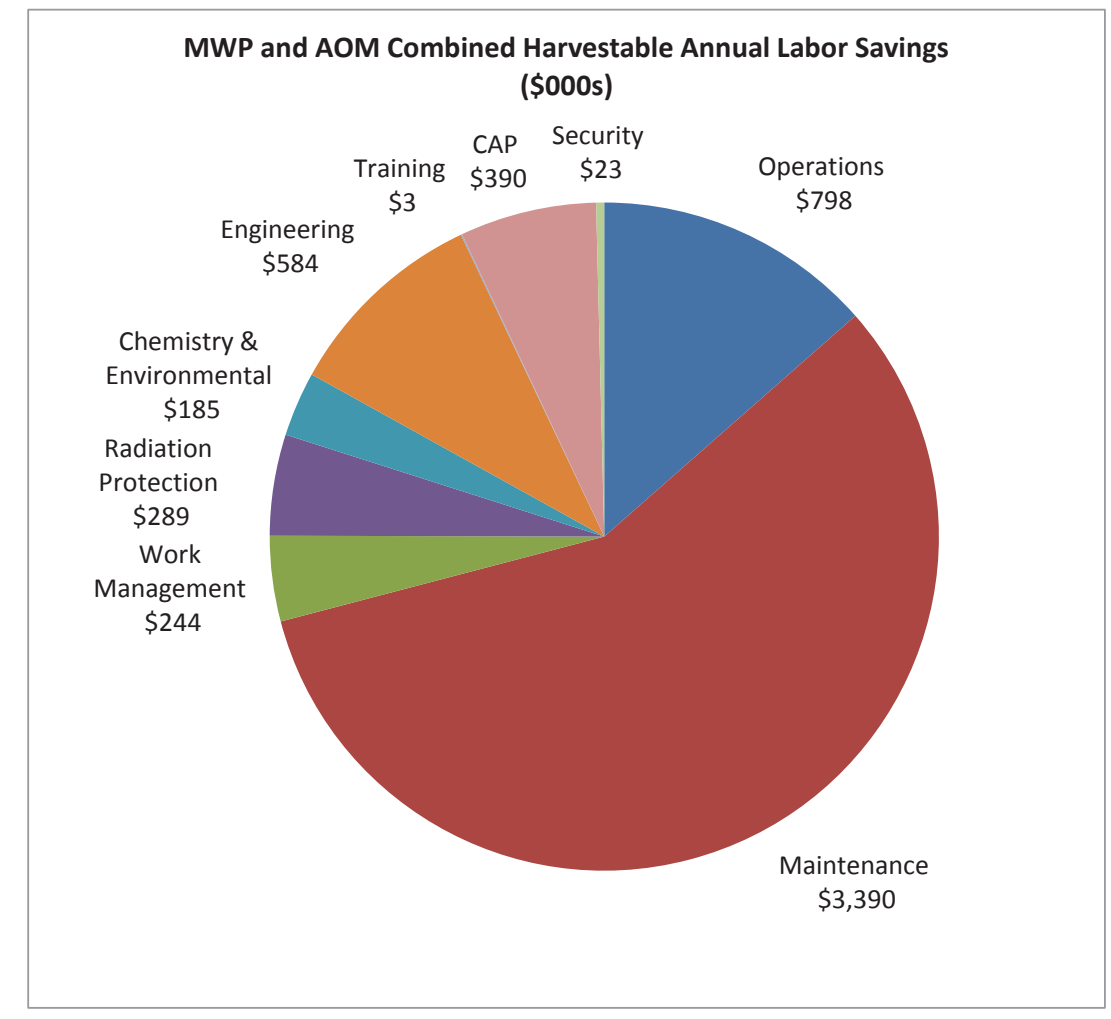

Figure 7: MWP and AOM Combined Harvestable Annual Labor Savings 


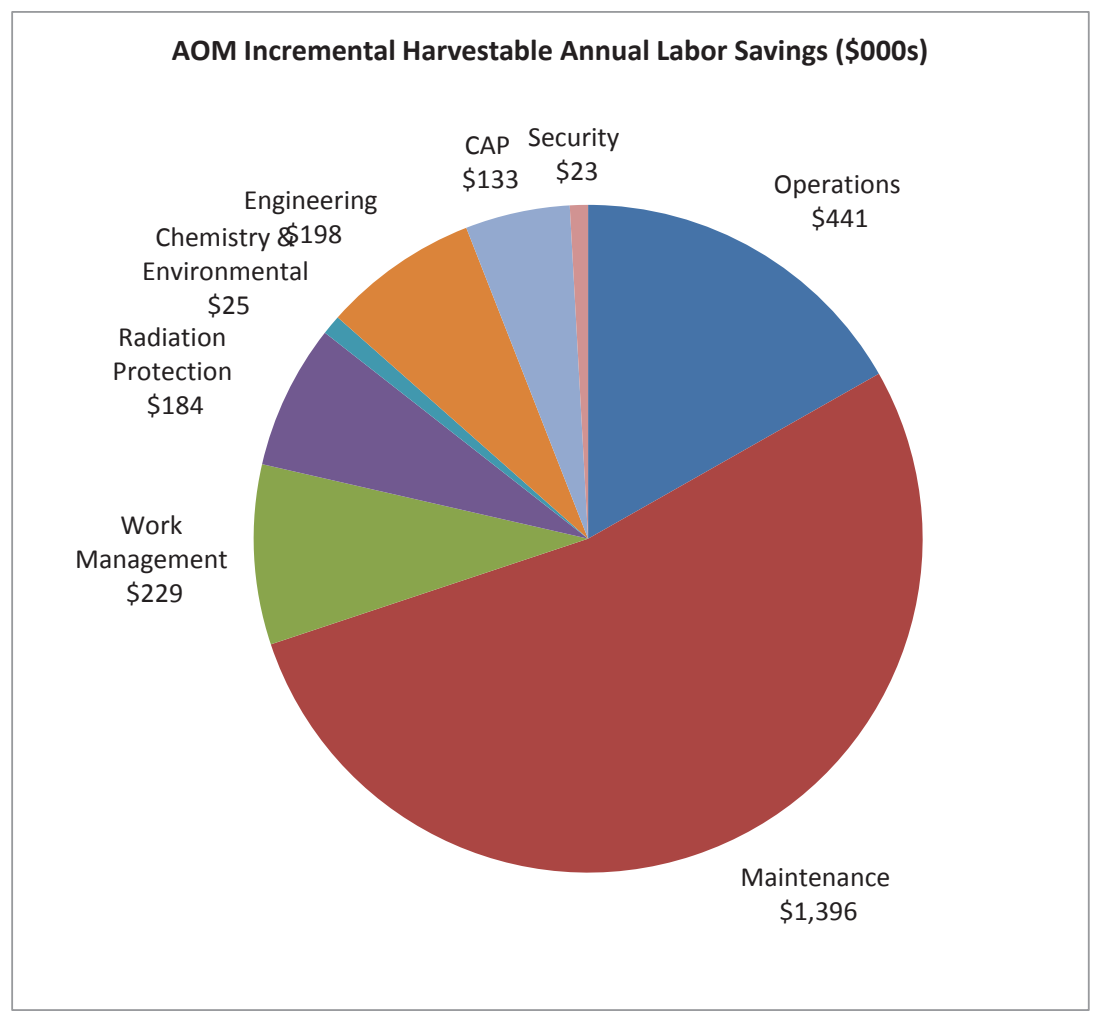

Figure 8: AOM Incremental Harvestable Annual Labor Savings

More detailed summaries of labor savings by work category and task level may be found in Appendix A and $\mathrm{B}$ of this report.

\subsection{Non-Labor Savings}

Non-labor savings were largely estimated in three categories:

1. The elimination of paper in work processes

2. The avoidance of contractor costs due to outage extension

3. The avoidance of purchase of replacement power due to outage extension

Paper savings were largely estimated as the elimination of printed work packages, drawings, schedule updates and meeting presentation materials, and the corresponding reduction of consumable office products that include but are not limited to paper, printer and plotter consumable supplies, printer and lotter maintenance. An all-in rate of 10 cents per standard sheet of paper was used as the cost of consumable produce paper deliverables.

Reduction in contractor labor costs is driven by better bulk work management and reduced risk of schedule extension. It was estimated that $30 \%$ of contractors will be released as on time due to schedule adherence enabled by bulk work optimization. 
Likewise, schedule adherence and timely restart of the NPP also allows the operator to avoid costly purchases of replacement power. Replacement power was roughly estimated as $\$ 400,000$ per day for a two-unit plant.

The vast majority of non-labor savings in the combined case is attributable to AOM at 1.88 million. Figure 9 below illustrates various categories of non-labor savings in relation to annual labor savings identified in the BCMW for MWP and AOM.

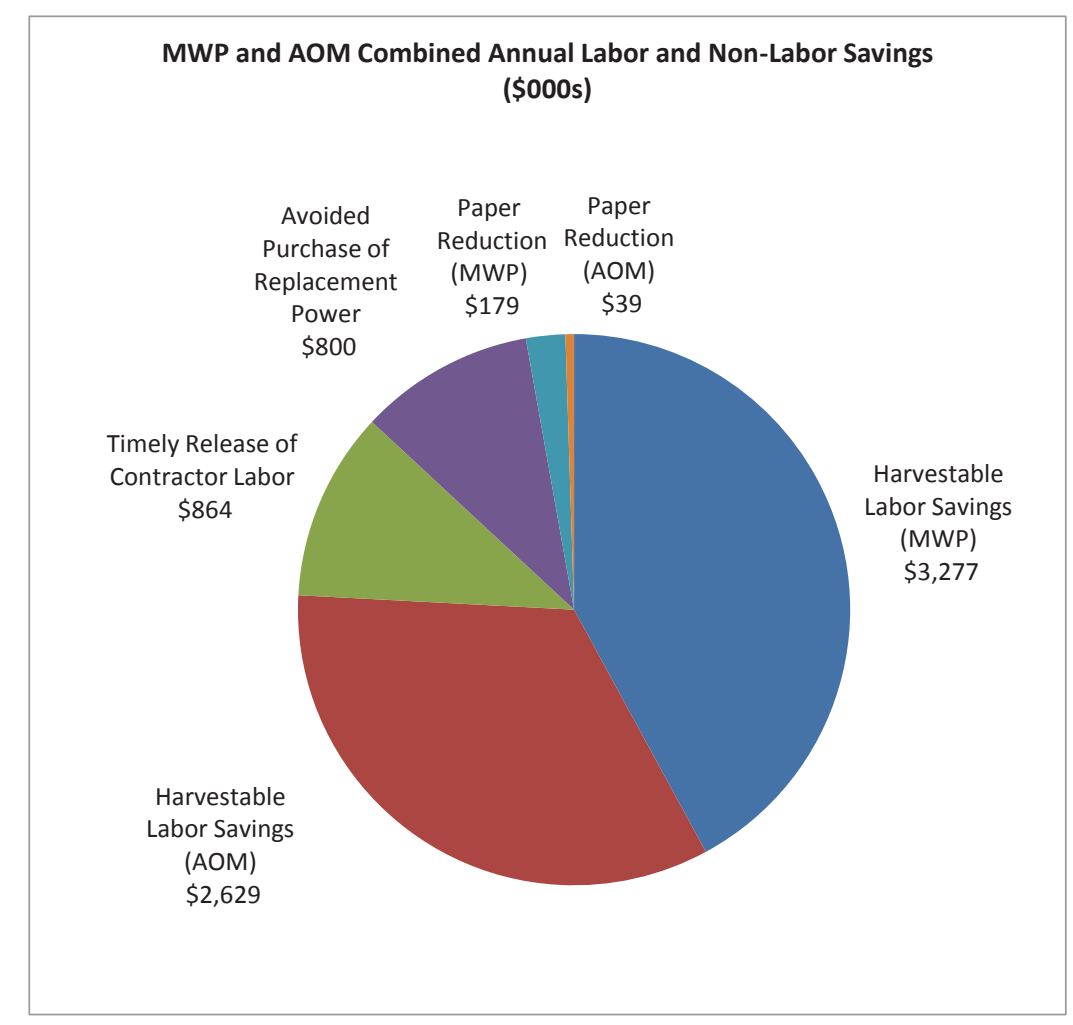

Figure 9: Non-Labor Savings in Relation to Labor Savings

\subsection{Estimation Present Value}

For guidance purposes, a present value tool included in the BCMW was utilized to estimate the incremental present value of AOM. AS the cost of the technology was not evaluated, the PV represents an approximate estimate of the investment that would produce a net zero value if Net Present Value (NPV) were utilized to evaluate a project. An investment lower than the present value would indicate a positive NPV project, while an investment higher than the present value would indicate a negative NPV project. The calculation assumes that the project benefits will not be fully realized until the third year of implementation at a discount rate of $10 \%$. Discounting over a period of 15 years, the present value tool indicates that an investment of $\$ 48$ million in MWP and AOM technologies would be with cost of up to $\$ 48$ million would be supported the estimated savings calculated in the business case. Table 2 below 
presents the overall results in terms of annual savings and present value derived from the BCM Present Value Estimating Tool.

Table 2: Annual Benefit and Present Value of MWP and AOM Business Cases

\begin{tabular}{|c|c|c|}
\hline \multicolumn{3}{|l|}{ Combined BCM } \\
\hline Discount Rate (Internal Rate of Return): & & $10 \%$ \\
\hline No. Years of Benefit: & & 15 years \\
\hline Annual Benefit (Labor) & $\$$ & 5.91 million \\
\hline Annual Benefit (Non-Labor) & $\$$ & 1.88 million \\
\hline Annual Benefit (KPI) & & $\mathrm{n} / \mathrm{a}$ million \\
\hline Total Annual Benefit: & $\$$ & 7.79 \\
\hline First Year Realized Benefit: & & 3 \\
\hline Estimated Net Zero NPV Investment: & & $\$ 48.96$ million \\
\hline \multicolumn{3}{|l|}{ Prior BCM (Mobile Work Packages) } \\
\hline Annual Benefit (Labor) & $\$$ & 3.28 million \\
\hline Annual Benefit (Non-Labor) & $\$$ & 0.18 million \\
\hline Annual Benefit (KPI) & & $\mathrm{n} / \mathrm{a}$ million \\
\hline Total Annual Benefit: & $\$$ & 3.46 \\
\hline Estimated Net Zero NPV Investment: & & $\$ 21.73$ million \\
\hline \multicolumn{3}{|l|}{ AOM BCM (Incremental Benefit) } \\
\hline Annual Benefit (Labor) & $\$$ & 2.63 million \\
\hline Annual Benefit (Non-Labor) & $\$$ & 1.70 million \\
\hline Annual Benefit (KPI) & & $\mathrm{n} / \mathrm{a}$ million \\
\hline Total Annual Benefit: & $\$$ & 4.33 \\
\hline Estimated Net Zero NPV Investment: & & $\$ 27.23$ million \\
\hline
\end{tabular}




\section{DISCUSSION}

\subsection{Human Performance Improvement}

A major benefit of the MWP and AOM technology, in addition to improved work efficiency, is the reduction in human error. Many human error prevention techniques can be built into the MWP technologies in a transparent manner that actually reduces operator burden over having to observe implement these practices in a manual mode.

Many types of procedure use and adherence issues can be directly prevented. For example, skipping steps or performing steps out of order can be detected and controlled by the software. Other types of preventable errors include ensuring that the performer qualifications are current and that all test equipment matches what is required by the procedure and its calibration due date has not passed.

Human error prevention is also a form of cost savings in that it precludes rework, corrective action program requirements such as cause analysis and corrective actions, and regulatory impacts. The human error prevention features of the MWP and AWP could be just as strong a motivation to implement the technology as the labor savings.

\subsection{Key Performance Indicators}

Although new values for improved KPIs could not be calculated as part of this study, several KPIs are likely positively impacted by the MWP and CBP technology as follows:

- Production Cost (\$/Megawatt-Hour) -due to direct reduction of O\&M expense related to field work activities and more generation days due to shorter outages

- Unit Capability Factor -shorter refueling outages due to improved work coordination

- Radiation Exposure - due to improved coordination efficiencies and less wait time for work activities performed in radiation areas 


\section{CONCLUSION}

The BCM was used to determine the value of AOM technologies if applied to a NPP. A worksheet was developed to help the team work through how various technologies impact outage operations. The resulting findings were validated at a participating operating NPP and then applied to the BCMW quantify the value of benefits of MWP and AOM. During the course of the study, several techniques for conducting analysis of work were developed and documented and improvements were made to the BCMW itself. The benefits of MWP and AOM were successfully quantified and the resulting NPV demonstrated that the continued development of the business case is warranted. In validating the BCM, the partner utility is provided with the basis for an internal business case for implementing these technologies based on identified work efficiencies that are harvestable through reduced contracted labor, overtime and headcount reductions over time. In addition, substantial non-labor savings were identified with improved capability to manage and optimize bulk work activities.

Through publication of the findings and the BCM, the nuclear industry is provided with a sample business case for pilot project technologies that can be used as a template for pursuing similar implementations at other nuclear plants. 


\section{REFERENCES}

1. Thomas, K., Lawrie S., Vlahapolis, C., and Niedermuller, J., 2015, Pilot Project Technology Business Case: Mobile Work Packages, INL/EXT-15-35327, Idaho National Laboratory.

2. Thomas, K., Lawrie S., Vlahapolis, C., and Hart, A., 2014, Digital TechnologyBusiness Case Methodology Guide, INL/EXT-14-33129, Idaho National Laboratory.

3. St. Germain, S., Thomas, K., Joe, J., Farris, R., 2014, Status Report on the Development of Micro-Scheduling Software for the Advanced Outage Control Center Project, INL/EXT-1433036, Idaho National Laboratory.

4. Rusaw, R., 2009, EPRI's Implementation Guideline for Wireless Networks and Wireless Equipment Condition Monitoring, Report No. 1019186, Electric Power Research Institute, Palo Alto, CA.

5. St. Germain, S., Farris, R., Whaley, A., Medema, H., Gertman, D., 2014, Guidelines for Implementation of an Advanced Outage Control Center to Improve Outage Coordination, Problem Resolution, and Outage Risk Management, INL/EXT-14-33182, Idaho National Laboratory. 


\section{Appendix A}

\section{Opportunity Worksheet}




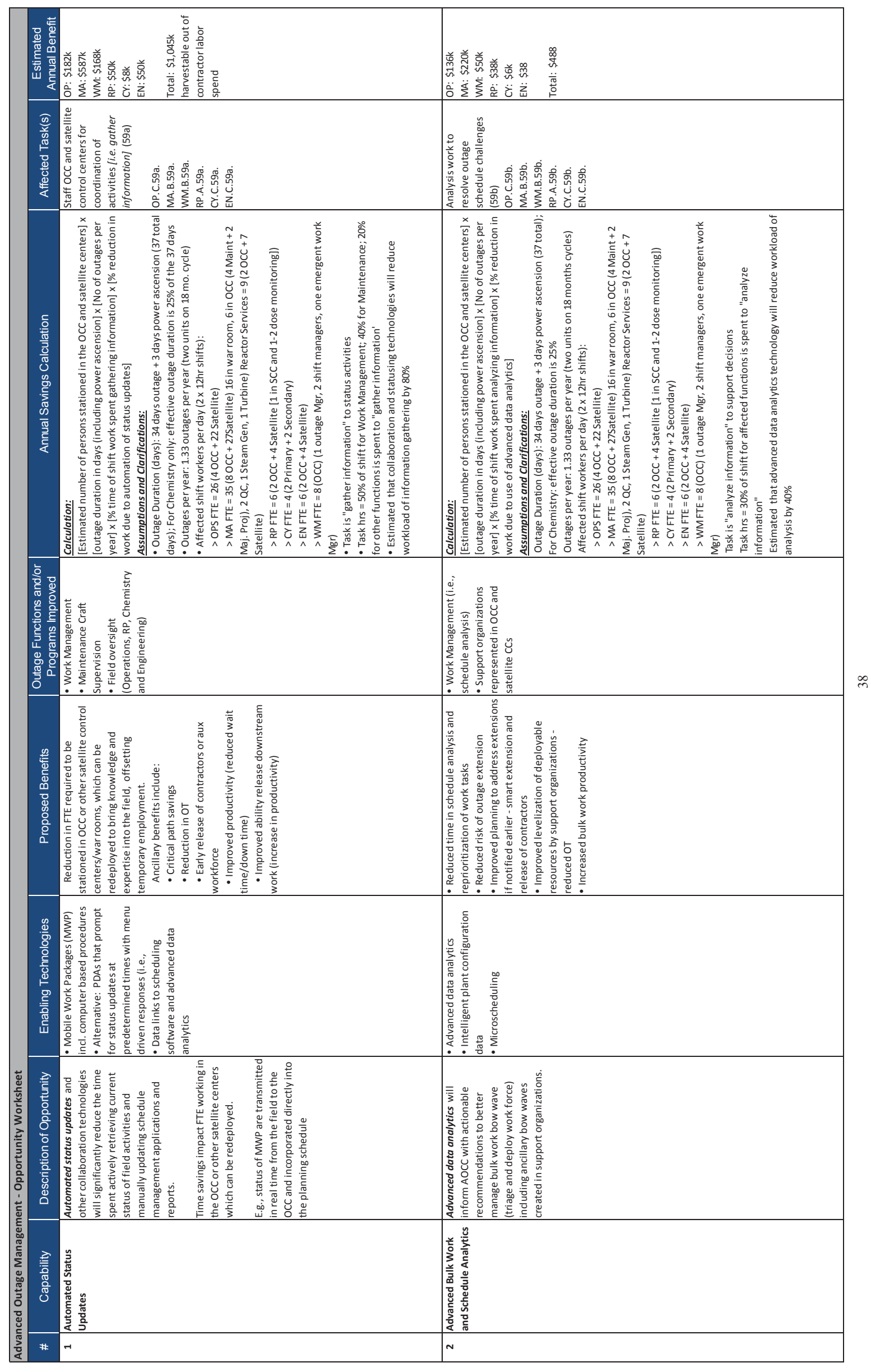




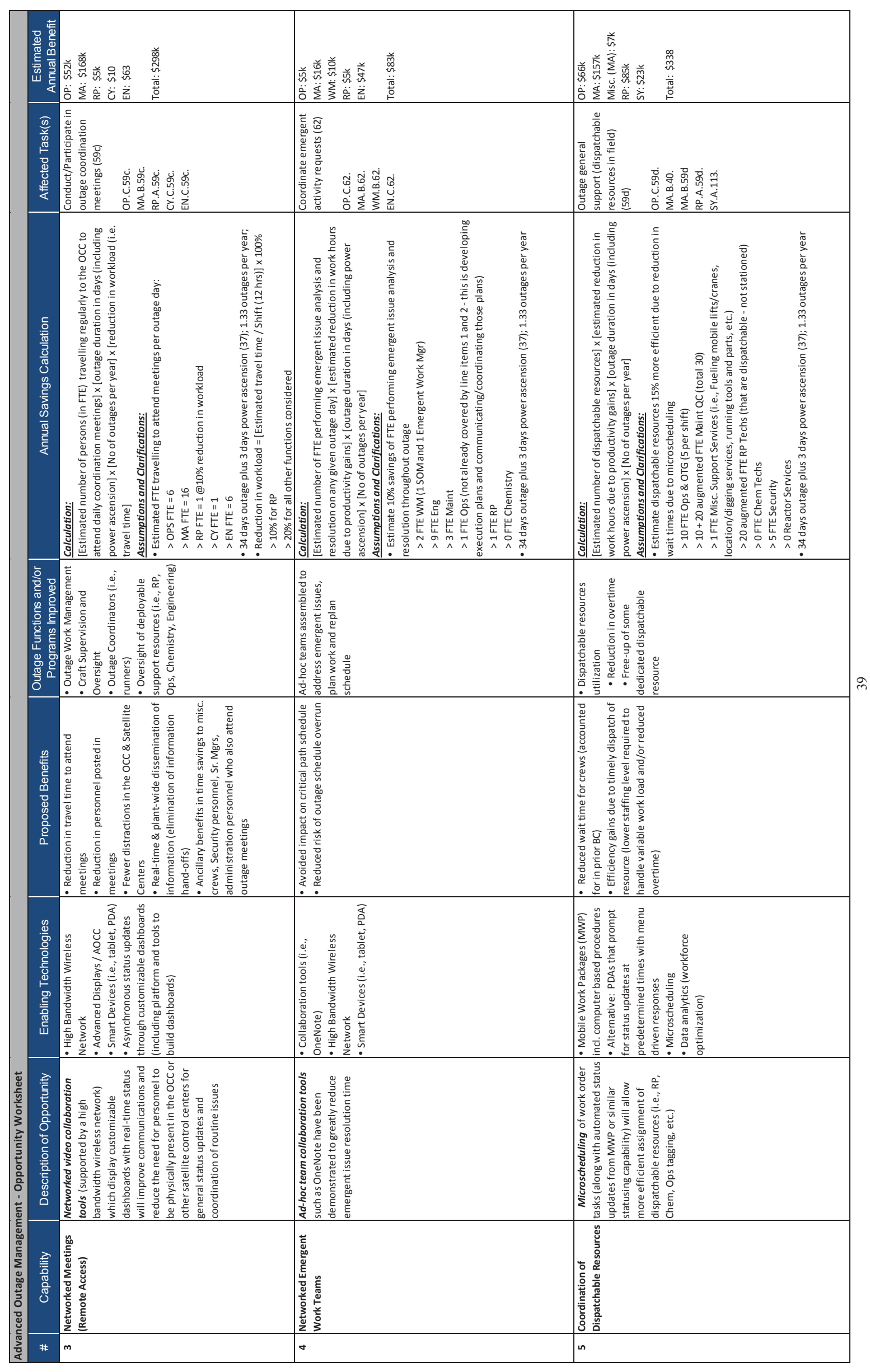




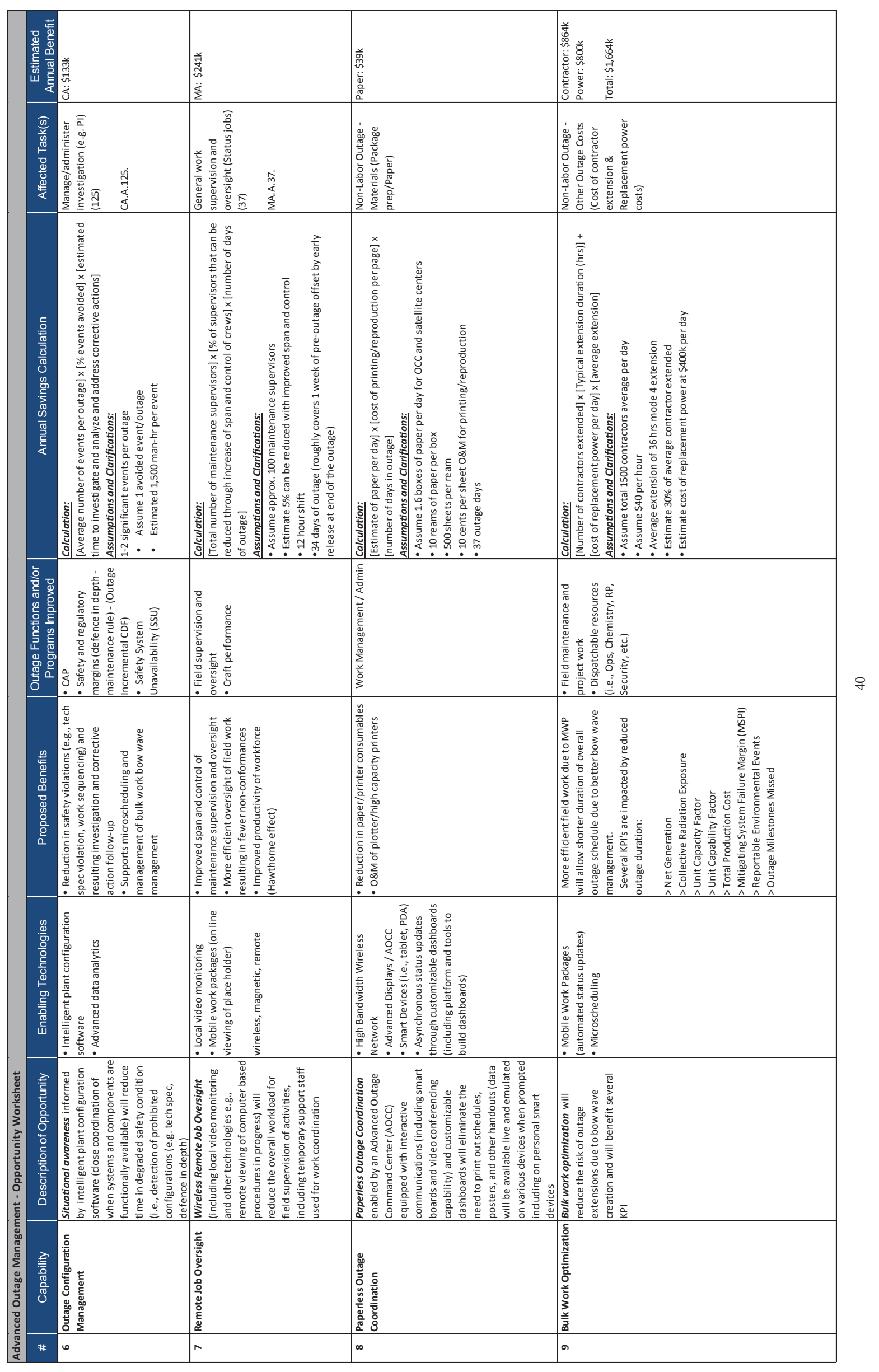


Appendix B

\section{Labor Cost Savings by Key Work Category}




\begin{tabular}{|c|c|c|c|c|c|c|c|c|c|c|c|c|c|}
\hline \multicolumn{11}{|c|}{ Labor Costs (Internal Labor, Overtime, Contractor Spend) } & \multicolumn{3}{|c|}{$\begin{array}{c}\text { Approximate Base } \\
\text { Organization Site } \\
\text { Size (FTEs) }\end{array}$} \\
\hline Functional Area & & Key Work Categories & $\begin{array}{c}\text { Total } \\
\text { Estimated } \\
\text { Savings } \\
\text { (person hrs) }\end{array}$ & \multicolumn{2}{|c|}{$\begin{array}{c}\text { Total } \\
\text { Estimated } \\
\text { Savings }(x \\
\$ 1,000)\end{array}$} & \multirow[t]{2}{*}{$\begin{array}{c}\text { Are savings } \\
\text { harvestable? } \\
\text { (Yes/No) } \\
\text { Yes }\end{array}$} & \multirow{2}{*}{\begin{tabular}{|c|}
$\%$ Harvestable \\
$100 \%$
\end{tabular}} & \begin{tabular}{|c} 
Total \\
Estimated \\
Savings \\
(FTEs)
\end{tabular} & \multicolumn{2}{|c|}{\begin{tabular}{|c|} 
Total \\
Estimated \\
Harvestable \\
Savings $(x$ \\
$\$ 1,000)$
\end{tabular}} & \multirow{2}{*}{\begin{tabular}{|c|}
1 Unit \\
27
\end{tabular}} & \multirow{2}{*}{$\frac{2 \text { Unit }}{33}$} & \multirow{2}{*}{$\frac{3 \text { Uni }}{40}$} \\
\hline \multirow[t]{6}{*}{ Operations } & OP.A. & Perform Field Operations & 3,893 & $\$$ & 288 & & & 1.9 & $\$$ & 288 & & & \\
\hline & OP.B. & Conduct Control Room Operations & - & $\$$ & - & & & 0.0 & $\$$ & - & 30 & 40 & 50 \\
\hline & OP.C. & Support Work Management & 5,952 & $\$$ & 441 & Yes & $100 \%$ & 2.9 & $\$$ & 441 & 5 & 6 & 11 \\
\hline & OP.D. & Perform Planning Activities & 1,884 & $\$$ & 85 & Yes & $80 \%$ & 0.7 & $\$$ & 68 & 5 & 6 & 10 \\
\hline & OP.E. & Perform Support Activities & - & $\$$ & - & & & 0.0 & $\$$ & - & 15 & 19 & 27 \\
\hline & OP.F. & Participate in Training & - & $\$$ & - & & & 0.0 & $\$$ & - & 11 & 14 & 20 \\
\hline \multirow[t]{8}{*}{ Maintenance } & MA.A. & Perform Maintenance Activities & 66,096 & $\$$ & 3,913 & Yes & $30 \%$ & 9.5 & $\$$ & 1,174 & 85 & 140 & 175 \\
\hline & MA.B. & Support Outage Oversight & 5,371 & $\$$ & 398 & Yes & $100 \%$ & 2.6 & $\$$ & 398 & 85 & 140 & 175 \\
\hline & MA.C. & Support Work Management & 11,249 & $\$$ & 998 & Yes & $100 \%$ & 5.4 & $\$$ & 998 & 4 & 7 & 9 \\
\hline & MA.D. & Perform Planning Activities & 12,375 & $\$$ & 543 & Yes & $80 \%$ & 4.8 & $\$$ & 435 & 18 & 30 & 37 \\
\hline & MA.E. & Perform Support Activities & 4,342 & $\$$ & 386 & Yes & $100 \%$ & 2.1 & $\$$ & 386 & 22 & 37 & 46 \\
\hline & MA.F. & Participate in Training & 272 & $\$$ & 16 & No & $0 \%$ & 0.0 & $\$$ & - & 10 & 16 & 20 \\
\hline & MA.G. & Calibrate Maintenance \& Test Equipm $\epsilon$ & - & $\$$ & - & & & 0.0 & $\$$ & - & 2 & 3 & 4 \\
\hline & MA.H. & Oversee Maintenance Program Implem & - & $\$$ & - & & & 0.0 & $\$$ & - & 2 & 3 & 4 \\
\hline \multirow{4}{*}{\begin{tabular}{|l|} 
Work \\
Management
\end{tabular}} & WM.A. & Manage Online Work & 1,374 & $\$$ & 102 & No & & 0.0 & $\$$ & - & 9 & 10 & 13 \\
\hline & WM.B. & Manage Outage Work & 2,787 & $\$$ & 244 & Yes & $100 \%$ & 1.3 & $\$$ & 244 & 6 & 7 & 9 \\
\hline & WM.c. & Manage Risk and Safety & 125 & $\$$ & 9 & No & $0 \%$ & 0.0 & $\$$ & - & 1 & 2 & 2 \\
\hline & WM.D. & Perform Support Activities & - & $\$$ & - & & & 0.0 & $\$$ & - & 5 & 8 & 11 \\
\hline \multirow{7}{*}{\begin{tabular}{|l|} 
Radiation \\
Protection
\end{tabular}} & RP.A. & Provide job coverage & 2,837 & $\$$ & 201 & Yes & $100 \%$ & 1.4 & $\$$ & 201 & 11 & 13 & 15 \\
\hline & & & & & & & & & & & & & \\
\hline & RP.B. & Maintain records & - & $\$$ & - & & & 0.0 & $\$$ & - & 4 & 5 & 7 \\
\hline & RP.C. & Maintain equipment & 1,495 & $\$$ & 88 & Yes & $100 \%$ & 0.7 & $\$$ & 88 & 6 & 8 & 11 \\
\hline & RP.D. & Package/control Radwaste & - & $\$$ & - & & & 0.0 & $\$$ & - & 5 & 8 & 10 \\
\hline & RP.E. & Plan Exposure of Jobs (ALARA) & - & $\$$ & - & & & 0.0 & $\$$ & - & 4 & 6 & 8 \\
\hline & RP.F. & Training Activities & - & $\$$ & - & & & 0.0 & $\$$ & - & 5 & 7 & 9 \\
\hline \multirow{5}{*}{$\begin{array}{l}\text { Chemistry \& } \\
\text { Environmental }\end{array}$} & CY.A. & Sample Systems & 613 & $\$$ & 36 & Yes & $100 \%$ & 0.3 & $\$$ & 36 & 8 & 9 & 13 \\
\hline & CY.B. & Data Evaluation and Trending & 548 & $\$$ & 32 & Yes & $100 \%$ & 0.3 & $\$$ & 32 & 6 & 7 & 9 \\
\hline & CY.C. & Operate and Maintain Equipment/Syst€ & 2,012 & $\$$ & 116 & Yes & $100 \%$ & 1.0 & $\$$ & 116 & 2 & 2 & 3 \\
\hline & CY.D. & RETS/REMP Program Monitoring & - & $\$$ & - & & & 0.0 & $\$$ & - & 3 & 3 & 4 \\
\hline & CY.E. & Training Activities & - & $\$$ & - & & & 0.0 & $\$$ & - & 3 & 3 & 5 \\
\hline \multirow[t]{4}{*}{ Engineering } & EN.A. & Perform Engineering activities & - & $\$$ & - & & & 0.0 & $\$$ & - & 36 & 43 & 52 \\
\hline & EN.B. & Monitor and report & 4,350 & $\$$ & 386 & Yes & $100 \%$ & 2.1 & $\$$ & 386 & 15 & 17 & 19 \\
\hline & EN.C. & Perform Support Activities & 2,232 & $\$$ & 198 & Yes & $100 \%$ & 1.1 & $\$$ & 198 & 37 & 40 & 46 \\
\hline & EN.D. & Training Activities & - & $\$$ & - & & & 0.0 & $\$$ & - & 2 & 2 & 3 \\
\hline Training & TR.A. & Conduct Training & - & $\$$ & - & & & 0.0 & $\$$ & - & 21 & 25 & 28 \\
\hline & TR.B. & Oversee Accreditation & - & $\$$ & - & & & 0.0 & $\$$ & - & 6 & 7 & 8 \\
\hline & TR.C. & Perform Support Activities & 400 & $\$$ & 13 & Yes & $25 \%$ & 0.0 & $\$$ & 3 & 8 & 10 & 13 \\
\hline & TR.D. & Training Activities & - & $\$$ & - & & & 0.0 & $\$$ & - & 4 & 5 & 6 \\
\hline Performance & PI.A. & Track and Trend Performance & - & $\$$ & - & & & 0.0 & $\$$ & - & 4 & 5 & 7 \\
\hline & PI.B. & Perform Support Activities & - & $\$$ & - & & & 0.0 & $\$$ & - & 4 & 5 & 6 \\
\hline Security \& Access & SY.A. & Maintain Physical Security & 443 & $\$$ & 23 & Yes & $100 \%$ & 0.2 & $\$$ & 23 & 180 & 190 & 200 \\
\hline & SY.B. & Control Access Authorization & - & $\$$ & - & & & 0.0 & $\$$ & - & 7 & 8 & 9 \\
\hline & SY.C. & Oversee Maintenance Program Implem & - & $\$$ & - & & & 0.0 & $\$$ & - & 5 & 6 & 7 \\
\hline Procedures & PR.A. & Manage procedure/program document: & - & $\$$ & - & & & 0.0 & $\$$ & - & 10 & 13 & 16 \\
\hline Emergency & EP.A. & Develop and Conduct Drills & - & $\$$ & - & & & 0.0 & $\$$ & - & 3 & 4 & 5 \\
\hline Preparedness & & & & & & & & & & & & & \\
\hline & EP.B. & Perform Support Activities & - & $\$$ & - & & & 0.0 & $\$$ & - & 2 & 3 & 4 \\
\hline Corrective Action & CA.A. & Process Condition Reports & 6,764 & $\$$ & 513 & Yes & $50 \%$ & 1.6 & $\$$ & 257 & 10 & 13 & 19 \\
\hline & CA.B. & Process Outage Related Events & 1,500 & $\$$ & 133 & Yes & $100 \%$ & 0.7 & $\$$ & 133 & 10 & 13 & 19 \\
\hline & CA.C. & Monitor and manage records & - & $\$$ & - & & & 0.0 & $\$$ & - & 5 & 7 & 8 \\
\hline & & Total Savings: & 138,912 & $\$$ & 9,165 & & & 40.5 & $\$$ & 5,907 & 768 & 1008 & 1232 \\
\hline
\end{tabular}




\section{Appendix C}

\section{Labor Cost Savings Summary Report}




\begin{tabular}{|c|c|c|c|c|c|c|c|}
\hline \multicolumn{6}{|c|}{ Labor Cost Savings Summary Report } & \multicolumn{2}{|l|}{ Note: Highlighted rows are associated with AOM technologies } \\
\hline \# & $\begin{array}{c}\text { Task } \\
\text { Number }\end{array}$ & Functional Area & Work Category: Task & \begin{tabular}{|l|} 
EstFTE \\
Savings
\end{tabular} & $\left|\begin{array}{c}\text { Est Labor } \\
\text { Savings } \\
(\times \$ 1,000)\end{array}\right|$ & Basis for Calculation & Key Enabling Technologies \\
\hline 1 & OP.A.141. & Operations: & $\begin{array}{l}\text { Perform Field Operations: } \\
>\text { Conduct Pre-Job Brief }\end{array}$ & 0.30 & $\$ \quad 47$ & $\begin{array}{l}\text { Basis: Emphasis on critical steps and operating experience can } \\
\text { be conveyed through the work package. Calculation: } 7,600 \text { Ops } \\
\text { work orders } \times 2 \text { workers for } 10 \text { minutes. Of that, estimated } 50 \% \\
\text { of wo require pre-job briefs with } 25 \% \text { time savings }\end{array}$ & $\begin{array}{l}\text { Control of steps and operator responses in a } \\
\text { Computer Based Procedure (CBP) (e.g., IIT OE in } \\
\text { pop-up window) }\end{array}$ \\
\hline 2 & OP.A.135b. & Operations: & $\begin{array}{l}\text { Perform Field Operations: } \\
>\text { Conduct surveillances and tests }\end{array}$ & 0.30 & 46 & $\begin{array}{l}3900 \text { Surveillance WOs from Maximo. Ave planned hours for } \\
\text { this work in Maximo is just over } 2 \text { hour in duration. Estimate } 8 \% \\
\text { time savings. }\end{array}$ & $\begin{array}{l}\text { General CBP features, especially remote } \\
\text { notifications, data sheets, computations and } \\
\text { verifications }\end{array}$ \\
\hline 3 & OP.A.3. & Operations: & $\begin{array}{l}\text { Perform Field Operations: } \\
>\text { Hang tags }\end{array}$ & 0.13 & 19 & $\begin{array}{l}25 \text { tag outs per week @ } 4 \text { hours - potentialy eliminate second } \\
\text { operator due to CV }\end{array}$ & $\begin{array}{l}\text { MWP/CBP features that verify correct component } \\
\text { and other performer actions such as } \\
\text { computations. Could also rely on remote } \\
\text { verifications through streaming video. }\end{array}$ \\
\hline 4 & OP.A.4. & Operations: & $\begin{array}{l}\text { Perform Field Operations: } \\
>\text { Remove tags }\end{array}$ & 0.13 & 19 & $\begin{array}{l}25 \text { tag outs per week @ } 4 \text { hours - potentialy eliminate second } \\
\text { operator due to CV }\end{array}$ & $\begin{array}{l}\text { MWP/CBP features that verify correct component } \\
\text { and other performer actions such as } \\
\text { computations. Could also rely on remote } \\
\text { verifications through streaming video. }\end{array}$ \\
\hline 5 & OP.A.5. & Operations: & $\begin{array}{l}\text { Perform Field Operations: } \\
\text { > Conduct Post-Maintenance Tests }\end{array}$ & 0.64 & 98 & $\begin{array}{l}\text { Estimated as } 40 \% \text { of all Mech and Elect WO from Maximo } \\
\text { require post maintenance tests. Each test estimated as } 4 \text { man- } \\
\text { hr on average. Estimated } 10 \% \text { time savings. }\end{array}$ & $\begin{array}{l}\text { Remote notifications to better coordinate time of } \\
\text { service. }\end{array}$ \\
\hline 6 & OP.A.6. & Operations: & $\begin{array}{l}\text { Perform Field Operations: } \\
\text { > Operate Equipment/Systems }\end{array}$ & 0.35 & 54 & \begin{tabular}{|l|}
$\begin{array}{l}\text { Estimated as } 20 \text { operations performed per day @ } 365 \text { DPY with } \\
\text { on average } 1 \mathrm{mhr} \text { for each operation. Estimated } 10 \% \text { time } \\
\text { savings }\end{array}$ \\
\end{tabular} & $\begin{array}{l}\text { General CBP features, especially those that } \\
\text { enhance coordination with the Control Room }\end{array}$ \\
\hline 7 & OP.A.145. & Operations: & $\begin{array}{l}\text { Perform Field Operations: } \\
>\text { Install/remove temp mods } \\
\text { (instrumentation, jumpers) for } \\
\text { testing/maintenance }\end{array}$ & 0.03 & $\$$ & Estimated as $30 \%$ of Ops Surveillances. & $\begin{array}{l}\text { General CBP features, especially those that } \\
\text { enhance coordination with the Control Room }\end{array}$ \\
\hline 8 & OP.C.59a. & Operations: & $\begin{array}{l}\text { Support Work Management: } \\
>\text { Staff OCC and satellite control centers } \\
\text { for coordination of activities }\end{array}$ & 1.18 & 182 & $\begin{array}{l}\text { Item (1) from Opportunity Sheet; Estimated } 11 \text { persons in } \\
\text { satellites and } 2 \text { in the OCC ( } 13 \text { per shift } \times 2 \text { shifts }=26 \text { total); } 34 \\
\text { days outage plus } 3 \text { days power assencion (37); } 1.33 \text { outages per } \\
\text { year; Estimate } 20 \% \text { of shift work is spent gathering information; } \\
\text { of that an } 80 \% \text { reduction in work due to automation of status } \\
\text { updates. }\end{array}$ & Automated status updates \\
\hline 9 & OP.C.59b. & Operations: & $\begin{array}{l}\text { Support Work Management: } \\
>\text { Analysis work to resolve outage } \\
\text { schedule challenges }\end{array}$ & 0.89 & 136 & $\begin{array}{l}\text { Item (2) from Opportunity Sheet; Estimated } 11 \text { persons in } \\
\text { satellite and } 2 \text { in the OCC ( } 13 \text { per shift } 22 \text { shifts = } 26 \text { total)); } 34 \\
\text { days outage plus } 3 \text { days power assencion ( } 37 \text { ); } 1.33 \text { outages per } \\
\text { year; Estimate } 30 \% \text { of shift work is spent analyzing information; } \\
\text { of that a } 40 \% \text { reduction in work due to advanced data analytics }\end{array}$ & Advanced data analytics \\
\hline 10 & OP.C.59c. & Operations: & $\begin{array}{l}\text { Support Work Management: } \\
>\text { Conduct/Participate in outage } \\
\text { coordination meetings }\end{array}$ & 0.34 & 52 & $\begin{array}{l}\text { Item (3) from Opportunity Sheet; Estimated } 6 \text { persons who } \\
\text { regularly attend coordination meetings; } 34 \text { days outage plus } 3 \\
\text { days power assencion ( } 37 \text { ); } 1.33 \text { outages per year; It is } \\
\text { estimated that networked collaboration tools that allow remote } \\
\text { access and participation in meetings will reduce workload by } \\
20 \%\end{array}$ & Networked collaboration tools \\
\hline 11 & OP.C.62. & Operations: & $\begin{array}{l}\text { Support Work Management: } \\
>\text { Coordinate emergent activity requests }\end{array}$ & 0.03 & 5 & $\begin{array}{l}\text { Item (4) from Opportunity Sheet; Estimated } 1 \text { person, } 34 \text { days } \\
\text { outage plus } 3 \text { days power assencion (37); } 1.33 \text { outages per hear; } \\
10 \% \text { reduction in time spent per issue using ad-hoc team } \\
\text { collaboration tools }\end{array}$ & Ad-hoc team collaboration tools \\
\hline 12 & OP.C.59d. & Operations: & $\begin{array}{l}\text { Support Work Management: } \\
>\text { Outage general support (dispatchable } \\
\text { resources in field) }\end{array}$ & 0.43 & 66 & $\begin{array}{l}\text { Item (5) from Opportunity Sheet; Estimated } 10 \text { persons } 15 \% \\
\text { more effienct due to reduction in wait times due to } \\
\text { microscheduling }\end{array}$ & Microscheduling \\
\hline 13 & OP.D.13. & Operations: & $\begin{array}{l}\text { Perform Planning Activities: } \\
>\text { Review/sign off on work packages }\end{array}$ & 0.20 & 37 & $\begin{array}{l}7600 \text { Ops Work Orders in Maximo get packages prepared. } \\
\text { Estimated } 10 \text { minutes Supervisor time per Work Package and } \\
33 \% \text { time savings per WP }\end{array}$ & Automated routing and archiving \\
\hline 14 & OP.D.46a. & Operations: & $\begin{array}{l}\text { Perform Planning Activities: } \\
\text { > Print and assemble work packages }\end{array}$ & 0.35 & 24 & \begin{tabular}{|l|}
7600 Ops Surveillances in Maximo get packages prepared. \\
Estimated 15 minutes Admin time per Work Package eliminated.
\end{tabular} & Automated generation of mobile work packages \\
\hline 15 & OP.D.46b. & Operations: & $\begin{array}{l}\text { Perform Planning Activities: } \\
>\text { Process and archive completed work } \\
\text { packages }\end{array}$ & 0.35 & 24 & $\begin{array}{l}7600 \text { Ops Surviellances in Maximo get packages prepared. } \\
\text { Estimated } 15 \text { minutes Admin time per Work Package. Of those } \\
25 \% \text { will require some follow-up. }\end{array}$ & $\begin{array}{l}\text { Automation of archiving of records directly to } \\
\text { Documentum }\end{array}$ \\
\hline 16 & MA.A.139. & Maintenance: & $\begin{array}{l}\text { Perform Maintenance Activities: } \\
\text { > Obtain Pre-Job Brief }\end{array}$ & 1.06 & 130 & $\begin{array}{l}\text { Basis: Emphasis on critical steps and operating experience can } \\
\text { be conveyed through the work package. Calculation: } 13,200 \\
\text { maint work orders } \times 2 \text { workers for } 20 \text { minutes with } 25 \% \text { time } \\
\text { savings }\end{array}$ & $\begin{array}{l}\text { Control of steps and operator responses in a } \\
\text { Computer Based Procedure (CBP) (e.g., JIT OE in } \\
\text { pop-up window) }\end{array}$ \\
\hline 17 & MA.A.35a. & Maintenance: & $\begin{array}{l}\text { Perform Maintenance Activities: } \\
>\text { Initial sign-on of work }\end{array}$ & 1.90 & 234 & $\begin{array}{l}\text { All wO require some sort of sign-on. Of those } 60 \% \text { can be } \\
\text { automated through remote sign-on (eliminating wating time in } \\
\text { control center) }\end{array}$ & Remote sign-on \\
\hline 18 & MA.A.13. & Maintenance: & $\begin{array}{l}\text { Perform Maintenance Activities: } \\
>\text { Review/sign off on work packages }\end{array}$ & 1.59 & 195 & $\begin{array}{l}\text { Based on one Maint worker at } 1 / 2 \text { hour per close out. Estimated } \\
\text { that there will be a } 50 \% \text { savings of work to close Maint WO. }\end{array}$ & $\begin{array}{l}\text { CBP features that ensure all steps and sign-offs } \\
\text { and elimination of unused sections, verification } \\
\text { of results, automation of data sheets, and } \\
\text { automated routing for supervisor approval }\end{array}$ \\
\hline 19 & MA.A.45b. & Maintenance: & $\begin{array}{l}\text { Perform Maintenance Activities: } \\
\text { > Replan work packages }\end{array}$ & 0.32 & 39 & $\begin{array}{l}\text { Estimated that } 5 \% \text { of WO need real-time replan resulting in } \\
\text { delay of } 1 \text { hour for } 2 \text { field workers; eliminates } 90 \% \text { of delay }\end{array}$ & $\begin{array}{l}\text { Mobile work package features that allow real } \\
\text { time markup and collaboration with planner }\end{array}$ \\
\hline 20 & MA.A.23. & Maintenance: & $\begin{array}{l}\text { Perform Maintenance Activities: } \\
>\text { Conduct Correct Component } \\
\text { verification }\end{array}$ & 12.67 & $\$ 1,560$ & $\begin{array}{l}\text { Assumes } 42 \% \text { WO }(20 \% \text { Mech/FIN \& } 55 \% \text { Elect//\&C) will no } \\
\text { longer need second technician or helper if verifications can be } \\
\text { done using barcode verification. Basis: } 20 \% \text { of all WO eliminate } \\
\text { second worker who is needed solely for verification }\end{array}$ & $\begin{array}{l}\text { MWP/CBP features that verify correct component } \\
\text { and other performer actions such as } \\
\text { computations. Could also rely on remote } \\
\text { verifications through streaming video. }\end{array}$ \\
\hline 21 & MA.A.26. & Maintenance: & $\begin{array}{l}\text { Perform Maintenance Activities: } \\
>\text { Sign in/out of clearances }\end{array}$ & 0.25 & 31 & $\begin{array}{l}\text { Assumes half of all Maint WO have (2) clearances actions sign- } \\
\text { on/out. Of those, } 10 \% \text { have a tag lift. } 2 \text { people x min. } 15 \\
\text { minutes to travel to clearance coordinator. Note: The overall } \\
\text { sign-in/out is performed in the shop and is not impacted by } \\
\text { WMP }\end{array}$ & $\begin{array}{l}\text { MWP/CBP feature that enables remote sign- } \\
\text { in/out of clearances from field location. }\end{array}$ \\
\hline 22 & MA.A.28. & Maintenance: & $\begin{array}{l}\text { Perform Maintenance Activities: } \\
>\text { Conduct field walkdown }\end{array}$ & 1.19 & 147 & $\begin{array}{l}\text { Assume } 75 \% \text { of WO require field walkdown, approx } 1 \mathrm{hr} \text { on } \\
\text { average. } 25 \% \text { of time saved due to automatic/ remote retrieval } \\
\text { of MWP, real-time markup in field, and automatic routing to the } \\
\text { planner for corrections. }\end{array}$ & $\begin{array}{l}\text { MWP/CBP features that enable remote document } \\
\text { access, markup, and routing to planner. }\end{array}$ \\
\hline 23 & MA.A.33a. & Maintenance: & $\begin{array}{l}\text { Perform Maintenance Activities: } \\
>\text { V Verify M\&TE }\end{array}$ & 1.07 & 132 & $\begin{array}{l}\text { Assumes } 2 \text { opportunities per WO eliminated saving } \\
\text { approximately } 10 \text { minutes per opportunity. Eliminates need to } \\
\text { compare M\&TE calabration sticker with calibration database and } \\
\text { to verify M\&TE matches what is specified in procedure. }\end{array}$ & Barcode and remote access to M\&TE data \\
\hline 24 & MA.A.36. & Maintenance: & $\begin{array}{l}\text { Perform Maintenance Activities: } \\
>\text { > Execute field work including clean up } \\
\text { area }\end{array}$ & 10.14 & $\$ 1,249$ & $\begin{array}{l}\text { Based on separate study estimating efficiency for executable } \\
\text { work of procedures. } 13,200 \text { maintenance procedures with ave. } \\
14.4 \text { planned hrs per WO. Refer to separate MAINT Estimate } \\
\text { Sheet }\end{array}$ & $\begin{array}{l}\text { CBP features that include smart-placekeeping, } \\
\text { smart-branching, automated computations, } \\
\text { automated notifications, remote authorizations, } \\
\text { remote access of reference information and } \\
\text { documents, and real-time coordination of support } \\
\text { groups such as QC. }\end{array}$ \\
\hline 25 & MA.A.43. & Maintenance: & $\begin{array}{l}\text { Perform Maintenance Activities: } \\
>\text { Close out work orders/work requests in } \\
\text { work management system }\end{array}$ & 1.59 & 195 & $\begin{array}{l}\text { Based on direct entry of closeout information (job } \\
\text { start/complete times, actual manhours and job comments) from } \\
\text { MWP/CBP. } 13,200 \text { WO at } 30 \text { min per closeout 50\% more } \\
\text { efficient. }\end{array}$ & $\begin{array}{l}\text { MWP/CBP features that enable direct access to } \\
\text { work management system. }\end{array}$ \\
\hline
\end{tabular}




\begin{tabular}{|c|c|c|c|c|c|c|c|c|}
\hline \multicolumn{7}{|c|}{ Labor Cost Savings Summary Report } & \multicolumn{2}{|l|}{ Note: Highlighted rows are associated with AOM technologies } \\
\hline \# & $\begin{array}{c}\text { Task } \\
\text { Number }\end{array}$ & Functional Area & Work Category: Task & $\begin{array}{l}\text { EstFTE } \\
\text { Savings }\end{array}$ & & $\begin{array}{l}\text { Labor } \\
\text { vings } \\
1,000)\end{array}$ & Basis for Calculation & Key Enabling Technologies \\
\hline 26 & MA.B.37. & Maintenance: & $\begin{array}{l}\text { Support Outage Oversight: } \\
>\text { Status jobs (esp. critical path) }\end{array}$ & 1.30 & $\$$ & 241 & $\begin{array}{l}\text { Item (7) on Opportunity Sheet; Estimated } 100 \text { crews could be } \\
\text { managed by } 5 \text { fewer supervisors due to local video monitoring }\end{array}$ & Wireless remote job oversight \\
\hline 27 & MA.B.40. & Maintenance: & $\begin{array}{l}\text { Support Outage Oversight: } \\
>\text { Validate/Witness QC hold-point } \\
\text { inspections }\end{array}$ & 1.28 & $\$$ & 157 & $\begin{array}{l}\text { Item (5) from Opportunity Sheet; Estimated } 30 \text { pers ons }(10+20 \\
\text { sugmented) QC } 15 \% \text { more effienct due to reduction in wait times } \\
\text { due to microscheduling }\end{array}$ & Microscheduling \\
\hline 28 & MA.C.59a. & Maintenance: & $\begin{array}{l}\text { Support Work Management: } \\
>\text { Staff OCC and satellite control centers } \\
\text { for coordination of activities }\end{array}$ & 3.18 & $\$$ & 587 & $\begin{array}{l}\text { Item (1) from Opportunity Sheet; Estimated } 13.5 \text { persons in } \\
\text { satellites and } 4 \text { in the OCC (17.5 per shift } \times 2 \text { shifts = } 35 \text { total); } \\
34 \text { days outage plus } 3 \text { days power assencion ( } 377) ; 1.33 \text { outages } \\
\text { per year; Estimate } 40 \% \text { of shift work is spent gathering } \\
\text { information; of that an } 80 \% \text { reduction in work due to automation } \\
\text { of status updates. }\end{array}$ & Automated status updates \\
\hline 29 & MA.C.59b. & Maintenance: & $\begin{array}{l}\text { Support Work Management: } \\
>\text { Analysis work to resolve outage } \\
\text { schedule challenges }\end{array}$ & 1.19 & $\$$ & 220 & $\begin{array}{l}\text { Item (2) from Opportunity Sheet; Estimated } 13.5 \text { persons in } \\
\text { satellite and } 4 \text { in the OCC (17.5 per shift } 22 \text { shifts }=35 \text { total); } 34 \\
\text { days outage plus } 3 \text { days power assencion ( } 377 \text { ); } 1.33 \text { outages per } \\
\text { year; Esitmate } 30 \% \text { of shift work is spent analyzing information; } \\
\text { of that a } 40 \% \text { reduction in work due to advanced data analytics }\end{array}$ & Advanced data analytics \\
\hline 30 & MA.C.59c. & Maintenance: & $\begin{array}{l}\text { Support Work Management: } \\
>\text { Conduct/Participate in outage } \\
\text { coordination meetings }\end{array}$ & 0.91 & $\$$ & 168 & $\begin{array}{l}\text { Item (3) from Opportunity Sheet; Estimated } 16 \text { pers ons who } \\
\text { regularly attend coordination meetings; } 34 \text { days outage plus } 3 \\
\text { days power assencion (37); } 1.33 \text { outages per year; It is } \\
\text { estimated that networked collaboration tools that allow remote } \\
\text { access and participation in meetings will reduce workload by } \\
20 \%\end{array}$ & Networked meeting collaboration tools \\
\hline 31 & MA.C.59d. & Maintenance: & $\begin{array}{l}\text { Support Work Management: } \\
>\text { Outage general support (dispatchable } \\
\text { resources in field) }\end{array}$ & 0.04 & $\$$ & & $\begin{array}{l}\text { Item (5) from Opportunity Sheet; Estimated a total one person } \\
\text { misc. support services (ile., fuieling, lifts, cranes, locaction/ } \\
\text { digging services, etc.) 15\% more effienct due to reduction in } \\
\text { wait times due to microscheduling }\end{array}$ & Microscheduling \\
\hline 32 & MA.C.62. & Maintenance: & $\begin{array}{l}\text { Support Work Management: } \\
>\text { Coordinate emergent activity requests }\end{array}$ & 0.09 & $\$$ & 16 & $\begin{array}{l}\text { Item (4) from Opportunity Sheet; Estimated } 1 \text { person, } 34 \text { days } \\
\text { outage plus } 3 \text { days power assencion ( } 377 \text {; } 1.33 \text { outages per hear; } \\
10 \% \text { reduction in time spent per issue using ad-hoc team } \\
\text { collaboration tools }\end{array}$ & Ad-hoc team collaboration tools \\
\hline 33 & MA.D.45a. & Maintenance: & $\begin{array}{l}\text { Perform Planning Activities: } \\
>\text { > Plan work packages }\end{array}$ & 1.90 & $\$$ & 264 & $\begin{array}{l}\text { Basis of } 13,200 \text { WO with an ave. of } 2 \text { hrs per WO. Estimate } 15 \% \\
\text { savings per plan due to improved ability to provide incorporate } \\
\text { information obtained during field walkdown (includes walkdown } \\
\text { time, interaction with craft) }\end{array}$ & $\begin{array}{l}\text { MWP/CBP features that enable remote document } \\
\text { access, field markup during planning walkdown }\end{array}$ \\
\hline 34 & MA.D.45b. & Maintenance: & $\begin{array}{l}\text { Perform Planning Activities: } \\
>\text { > Replan work packages }\end{array}$ & 0.08 & $\$$ & 11 & $\begin{array}{l}\text { Estimated that } 5 \% \text { of WO need real-time replan. Efficiency due } \\
\text { to automatic notification and markups from field and routing } \\
\text { back to field location. }\end{array}$ & $\begin{array}{l}\text { Mobile work package features that allow real } \\
\text { time markup and collaboration with planner }\end{array}$ \\
\hline 35 & MA.D.46a. & Maintenance: & $\begin{array}{l}\text { Perform Planning Activities: } \\
\text { > Print and assemble work packages }\end{array}$ & 1.59 & $\$$ & 107 & $\begin{array}{l}\text { Assumes all packages will be able to be issued as MWP. } \\
\text { Roughly equivalent to } 35 \% \text { of Admin time }\end{array}$ & MWP automated generation \\
\hline 36 & MA.D.46b. & Maintenance: & $\begin{array}{l}\text { Perform Planning Activities: } \\
>\text { Process and archive completed work } \\
\text { packages }\end{array}$ & 2.38 & $\$$ & 161 & $\begin{array}{l}\text { Assumes } 25 \% \text { of packages require some followup } \\
\text { processing.Roughly equivalent to } 65 \% \text { of Admin time. }\end{array}$ & MWP automated processing archiving \\
\hline 37 & MA.E.141. & Maintenance: & $\begin{array}{l}\text { Perform Support Activities: } \\
>\text { > Conduct Pre-Job Brief }\end{array}$ & 0.52 & $\$$ & 97 & $\begin{array}{l}\text { Basis: Emphasis on critical steps and operating experience can } \\
\text { be conveyed through the work package. Calculation: } 13,200 \\
\text { maint work orders } \times 2 \text { workers for } 20 \text { minutes with } 25 \% \text { time } \\
\text { savings }\end{array}$ & $\begin{array}{l}\text { Control of steps and operator responses in a } \\
\text { Computer Based Procedure (CBP) (e.g., IIT OE in } \\
\text { pop-up window) }\end{array}$ \\
\hline 38 & MA.E.140b. & Maintenance: & $\begin{array}{l}\text { Perform Support Activities: } \\
\text { > Verify Qualifications }\end{array}$ & 0.79 & $\$$ & 147 & $\begin{array}{l}\text { This is a supervisor action that is eliminated due to auto- } \\
\text { verification of quals during job initiation @ } 5 \mathrm{~min} \text {. per worker. }\end{array}$ & MWP/CBP access of remote databases. \\
\hline 39 & MA.E.136. & Maintenance: & $\begin{array}{l}\text { Perform Support Activities: } \\
\text { > Sign off work orders/procedures }\end{array}$ & 0.52 & $\$$ & 97 & $\begin{array}{l}\text { Efficiency due to direct routing to supervisors mobile platform } \\
\text { and elimination of PU\&A error checking. }\end{array}$ & $\begin{array}{l}\text { Automated routing and MWP/CBP features } \\
\text { addressing human error }(\mathrm{HU}) \text {. }\end{array}$ \\
\hline 40 & MA.E.59. & Maintenance: & $\begin{array}{l}\text { Perform Support Activities: } \\
>\text { > Monitor work progress/execution }\end{array}$ & 0.25 & $\$$ & 46 & $\begin{array}{l}\text { Based on } 3100 \text { outage WO and } 10 \% \text { of Tech Spec-related online } \\
\text { WOs. }\end{array}$ & $\begin{array}{l}\text { Real-time collaboration and direct viewing of } \\
\text { MWP/CBP in progress as well as automated real- } \\
\text { time status updates to schedule at predefined } \\
\text { status points }\end{array}$ \\
\hline 41 & MA.F.142. & Maintenance: & $\begin{array}{l}\text { Participate in Training: } \\
>\text { Participate in training }\end{array}$ & 0.13 & $\$$ & 16 & $\begin{array}{l}2 \% \text { reduction resulting from procedure automation. Based on } \\
136 \text { technicians } \times 100 \mathrm{hrs} / \mathrm{yr} \text {; only the features that would } \\
\text { reduce training elapsed time during training. }\end{array}$ & $\begin{array}{l}\text { CBP features that include smart-placekeeping, } \\
\text { smart-branching, automated computations, and } \\
\text { smart datasheets. }\end{array}$ \\
\hline 42 & WM.A.59. & Work Management: & $\begin{array}{l}\text { Manage Online Work: } \\
>\text { > Monitor work progress/execution }\end{array}$ & 0.66 & $\$$ & 102 & $\begin{array}{l}\text { Basis is } 20,100 \text { on-line WO at } 5 \text { minutes of monitoring each. } \\
80 \% \text { of the work can be passively monitored due to auto- } \\
\text { statusing. Of the remaining } 20 \% \text {, task is } 50 \% \text { more efficient due } \\
\text { to real-time collaboration }\end{array}$ & $\begin{array}{l}\text { Automated work statusing and real-time } \\
\text { collaboration. }\end{array}$ \\
\hline 43 & WM.B.59. & Work Management: & $\begin{array}{l}\text { Manage Outage Work: } \\
\text { > Monitor work progress/execution }\end{array}$ & 0.10 & $\$$ & 16 & $\begin{array}{l}\text { Basis is 3,100 outage WO at } 5 \text { minutes of monitoring each. } 80 \% \\
\text { of the work can be passively monitored due to auto-statusing. } \\
\text { of the remaining } 20 \% \text {, task is } 50 \% \text { more efficient due to real- } \\
\text { time collaboration }\end{array}$ & $\begin{array}{l}\text { Automated work statusing and real-time } \\
\text { collaboration. }\end{array}$ \\
\hline 44 & WM.B.59a. & Work Management: & $\begin{array}{l}\text { Manage Outage Work: } \\
>\text { Staff OCC and satellite control centers } \\
\text { for coordination of activities }\end{array}$ & 0.91 & $\$$ & 168 & $\begin{array}{l}\text { Item (1) from Opportunity Sheet; Estimated } 8 \text { persons in the OCC } \\
\text { ( } 4 \text { per shift } \times 2 \text { shifts }=8 \text { total); } 34 \text { days outage plus } 3 \text { days } \\
\text { power assencion }(37) ; 1.33 \text { outages per year; Estimate } 50 \% \text { of } \\
\text { shift work is spent gathering information; of that an } 80 \% \\
\text { reduction in work due to automation of status updates. }\end{array}$ & Automated status updates \\
\hline 45 & WM.B.59b. & Work Management: & $\begin{array}{l}\text { Manage Outage Work: } \\
>\text { Analysis work to resolve outage } \\
\text { schedule challenges }\end{array}$ & 0.27 & $\$$ & $50 \mid \begin{array}{lll}1 \\
i \\
i \\
i\end{array}$ & $\begin{array}{l}\text { Item (2) from Opportunity Sheet; Estimated } 8 \text { persons in the OCC } \\
\text { ( } 4 \text { per shift } x 2 \text { shifts }=8 \text { total); } 34 \text { days outage plus } 3 \text { days } \\
\text { power assencion }(37) ; 1.33 \text { outages per year; Esitmate } 30 \% \text { of } \\
\text { shift work is spent analyzing information; of that a } 40 \% \\
\text { reduction in work due to advanced data analytics }\end{array}$ & Advanced data analytics \\
\hline 46 & WM.B.62. & Work Management: & $\begin{array}{l}\text { Manage Outage Work: } \\
>\text { > Coordinate emergent activity requests }\end{array}$ & 0.06 & $\$$ & 10 & $\begin{array}{l}\text { Item (4) from Opportunity Sheet; Estimated } 1 \text { person, } 34 \text { days } \\
\text { outage plus } 3 \text { days power assencion (37); } 1.33 \text { outages per hear; } \\
10 \% \text { reduction in time spent per issue using ad-hoc team } \\
\text { collaboration tools }\end{array}$ & Ad-hoc team collaboration tools \\
\hline 47 & WM.C.67. & Work Management: & $\begin{array}{l}\text { Manage Risk and Safety: } \\
\text { > Minimize emergent work risk }\end{array}$ & 0.06 & $\$$ & 9 & $\begin{array}{l}\text { Estimated } 500 \text { emergent work items per year requiring risk } \\
\text { review with } 1 \mathrm{hr} \text { to perform. Estimate } 25 \% \text { efficiency gain due to } \\
\text { ability to collaborate real-time with multiple parties. }\end{array}$ & Real-time collaboration and video streaming. \\
\hline 48 & RP.A.68. & Radiation Protection: & $\begin{array}{l}\text { Provide job coverage: } \\
>\text { RP dose monitoring/ dose } \\
\text { measurements, samples etc. }\end{array}$ & 0.14 & $\$$ & 17 & $\begin{array}{l}\text { Reduction of } 11 \% \text { of the stay time during the execution portion } \\
\text { only. Based on } 2 \% \text { of all maintenance Wo ( } 264 \text { jobs) per year ( } \\
\text { approximately } 2 \text { per day) }\end{array}$ & $\begin{array}{l}\text { CBP features that include smart-placekeeping, } \\
\text { smart-branching, automated computations, } \\
\text { automated notifications, remote authorizations, } \\
\text { remote access of reference information and } \\
\text { documents, and real-time coordination of support } \\
\text { groups such as QC. }\end{array}$ \\
\hline 49 & RP.A.59a. & Radiation Protection: & $\begin{array}{l}\text { Provide job coverage: } \\
>\text { Staff OCC and satellite control centers } \\
\text { for coordination of activities }\end{array}$ & 0.27 & $\$$ & 20 & $\begin{array}{l}\text { Item (1) from Opportunity Sheet; Estimated } 2 \text { persons in the OCC } \\
\text { and } 4 \text { in satellites }(3 \text { per shift } \times 2 \text { shifts }=6 \text { total); } 34 \text { days } \\
\text { outage plus } 3 \text { days power assencion }(37) ; 1.33 \text { outages per year; } \\
\text { Estimate } 20 \% \text { of shift work is spent gathering information; of } \\
\text { that an } 80 \% \text { reduction in work due to automation of status } \\
\text { updates. }\end{array}$ & Automated status updates \\
\hline 50 & RP.A.59b. & Radiation Protection: & $\begin{array}{l}\text { Provide job coverage: } \\
>\text { Analysis work to resolve outage } \\
\text { schedule challenges }\end{array}$ & 0.20 & $\$$ & 38 & $\begin{array}{l}\text { Item (2) from Opportunity Sheet; Estimated } 2 \text { persons in satellite } \\
\text { and } 4 \text { in the OCC ( } 3 \text { per shift } \times 2 \text { shifts }=6 \text { total); } 34 \text { days outage } \\
\text { plus } 3 \text { days power assencion ( } 37) ; 1.33 \text { outages per year; } \\
\text { Esitmate } 30 \% \text { of shift work is spent analyzing information; of } \\
\text { that a } 40 \% \text { reduction in work due to advanced data analytics }\end{array}$ & Advanced Data Analytics \\
\hline
\end{tabular}




\begin{tabular}{|c|c|c|c|c|c|c|c|}
\hline \multicolumn{6}{|c|}{ Labor Cost Savings Summary Report } & \multicolumn{2}{|l|}{ Note: Highlighted rows are associated with AOM technologies } \\
\hline$\#$ & $\begin{array}{l}\text { Task } \\
\text { Number }\end{array}$ & Functional Area & Work Category: Task & $\begin{array}{l}\text { EstFTE } \\
\text { Savings }\end{array}$ & $\left|\begin{array}{c}\text { Est Labor } \\
\text { Savings } \\
(x \$ 1,000)\end{array}\right|$ & Basis for Calculation & Key Enabling Technologies \\
\hline 51 & RP.A.59c. & Radiation Protection: & $\begin{array}{l}\text { Provide job coverage: } \\
>\text { Conduct/Participate in outage } \\
\text { coordination meetings }\end{array}$ & 0.03 & 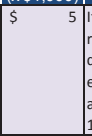 & $\begin{array}{l}\text { Item (3) from Opportunity Sheet; Estimated } 1 \text { person who } \\
\text { regularly attend coordination meetings; } 34 \text { days outage plus } 3 \\
\text { days power assencion ( } 377) ; 1.33 \text { outages per year; It is } \\
\text { estimated that networked collaboration tools that allow remote } \\
\text { access and participation in meetings will reduce workload by } \\
10 \%\end{array}$ & Networked meeting collaboration tools \\
\hline 52 & RP.A.59d. & Radiation Protection: & $\begin{array}{l}\text { Provide job coverage: } \\
>\text { Outage general support (dispatchable } \\
\text { resources in field) }\end{array}$ & 0.69 & 85 |1 & $\begin{array}{l}\text { Item (5) from Opportunity Sheet; Estimated } 20 \text { persons } 15 \% \\
\text { more effienct due to reduction in wait times due to } \\
\text { microscheduling (effective over } 30 \text { of the } 37 \text { outage days) }\end{array}$ & Microscheduling \\
\hline 53 & RP.A.62. & Radiation Protection: & $\begin{array}{l}\text { Provide job coverage: } \\
>\text { > coordinate emergent activity requests }\end{array}$ & 0.03 & $\$$ & $\begin{array}{l}\text { Item (4) from Opportunity Sheet; Estimated } 1 \text { person, } 34 \text { days } \\
\text { outage plus } 3 \text { days power assencion (37); } 1.33 \text { outages per hear; } \\
10 \% \text { reduction in time spent per issue using ad-hoc team } \\
\text { collaboration tools }\end{array}$ & Ad-hoc team collaboration tools \\
\hline 54 & RP.C.133. & Radiation Protection: & $\begin{array}{l}\text { Maintain equipment: } \\
\text { > Calibrate equipment }\end{array}$ & 0.02 & $3 \sqrt[3]{2}$ & $\begin{array}{l}200 \text { meters annual calibration @ } 1 \mathrm{hr} \text { per calibration made 25\% } \\
\text { more efficient. }\end{array}$ & $\begin{array}{l}\text { Automated data-sheets; CBP features especially } \\
\text { of smart datasheets, automated computations, } \\
\text { smart branching, automated notifications, and } \\
\text { automated routing. }\end{array}$ \\
\hline 55 & RP.C.74. & Radiation Protection: & $\begin{array}{l}\text { Maintain equipment: } \\
>\text { Routine surveys/surveillances }\end{array}$ & 0.58 & 71 e & $\begin{array}{l}\text { Based on } 33 \text { surveys per day @ } 1 \mathrm{hr} \text { each survey with 10\% } \\
\text { efficiency gain }\end{array}$ & $\begin{array}{l}\text { Automated survey map markup features and } \\
\text { editing in field }\end{array}$ \\
\hline 56 & RP.C.135b. & Radiation Protection: & $\begin{array}{l}\text { Maintain equipment: } \\
>\text { Conduct surveillances and tests }\end{array}$ & 0.12 & $14 \mid \begin{array}{lll}s & \\
n \\
e \\
e \\
b\end{array}$ & $\begin{array}{l}\text { Surveillances of radiation monitors (50 monitors per unit with } \\
\text { monthly surveillance) @ w hrs per surveillance made } 10 \% \text { more } \\
\text { efficient. Source check, respitory equipment kits, inventory of } \\
\text { boxes with material, vacuum cleaners, etc. }\end{array}$ & $\begin{array}{l}\text { CBP features especially of smart datasheets, } \\
\text { automated computations, smart branching, } \\
\text { automated notifications, and automated routing. }\end{array}$ \\
\hline 57 & CY.A.85. & $\begin{array}{l}\text { Chemistry \& } \\
\text { Environmental: }\end{array}$ & $\begin{array}{l}\text { Sample Systems: } \\
\text { > Chemistry samples and analysis }\end{array}$ & 0.21 & $26 \mid \begin{array}{ll}1 \\
a \\
t\end{array}$ & $\begin{array}{l}\text { No of samples based on } 6 \text { samples per day, } 365 \text { days per week } \\
\text { at } 2 \text { hours per sample. Sampling made } 10 \% \text { more efficient due } \\
\text { to CBP. }\end{array}$ & $\begin{array}{l}\text { CBP features especially of smart datasheets, } \\
\text { automated computations, smart branching, } \\
\text { automated notifications, automated routing, } \\
\text { automated component verification, access to } \\
\text { reference information, and remote ops } \\
\text { notifications. }\end{array}$ \\
\hline 58 & CY.A.86. & $\begin{array}{l}\text { Chemistry \& } \\
\text { Environmental: }\end{array}$ & $\begin{array}{l}\text { Sample Systems: } \\
>\text { Monitor effluent/environmental } \\
\text { stations }\end{array}$ & 0.08 & 10 & $\begin{array}{l}\text { Approx } 12 \text { environmental stations monitored daily at } 1 / 2 \text { hour } \\
\text { each with } 8 \% \text { efficiency gain }\end{array}$ & $\begin{array}{l}\text { Effieciencies due to automation of data sheets, } \\
\text { automated computations, pre and post } \\
\text { processing of procedures. Error elimination with } \\
\text { use of bar codes at stations }\end{array}$ \\
\hline 59 & CY.B.89. & $\begin{array}{l}\text { Chemistry \& } \\
\text { Environmental: }\end{array}$ & $\begin{array}{l}\text { Data Evaluation and Trending: } \\
\text { > Data evaluation and trending of system }\end{array}$ & 0.26 & 32 & $\begin{array}{l}\text { Time to transfer sample data into trending system is eliminated } \\
\text { (see CY-A-85 above). }\end{array}$ & Automated interface to databases. \\
\hline 60 & Cr.C.90. & $\begin{array}{l}\text { Chemistry \& } \\
\text { Environmental: }\end{array}$ & $\begin{array}{l}\text { Operate and Maintain Equipment/Systems: } \\
>\text { Maintain instrumentation }\end{array}$ & 0.30 & 37 & $\begin{array}{l}\text { Maintain DRMS Systems (PERMS - Plant Effluent Radiation } \\
\text { Monitoring System) @ } 60 \text { hrs per week made 20\% more efficient } \\
\text { due to CBP features. }\end{array}$ & $\begin{array}{l}\text { CBP features especially of smart datasheets, } \\
\text { automated computations, smart branching, } \\
\text { automated notifications, automated routing, } \\
\text { automated component verification, access to } \\
\text { reference information, and remote ops } \\
\text { notifications. }\end{array}$ \\
\hline 61 & CY.C.135b. & \begin{tabular}{|l|} 
Chemistry \& \\
Environmental:
\end{tabular} & $\begin{array}{l}\text { Operate and Maintain Equipment/Systems: } \\
>\text { Conduct surveillances and tests }\end{array}$ & 0.05 & $7 \mid \begin{array}{ll}\mathrm{B} \\
\mathrm{s}\end{array}$ & $\begin{array}{l}\text { Based on } 1300 \text { surveillance (from Maximo data) at } 1.1 \mathrm{hrs} \text { per } \\
\text { surveillance made } 8 \% \text { more efficient. }\end{array}$ & $\begin{array}{l}\text { General CBP features, especially those that } \\
\text { enhance coordination with the Control Room }\end{array}$ \\
\hline 62 & CY.C.46a. & $\begin{array}{l}\text { Chemistry \& } \\
\text { Environmental: }\end{array}$ & $\begin{array}{l}\text { Operate and Maintain Equipment/Systems: } \\
\text { > Print and assemble work packages }\end{array}$ & 0.12 & $\$$ & Approx 1000 work packages at 15 min each eliminated from work & MWP automated generation \\
\hline 63 & CY.C.46b. & $\begin{array}{l}\text { Chemistry \& } \\
\text { Environmental: }\end{array}$ & $\begin{array}{l}\text { Operate and Maintain Equipment/Systems: } \\
>\text { Process and archive completed work } \\
\text { packages }\end{array}$ & 0.18 & 12 & Approx 1000 work packages with $75 \%$ work time saved & MWP automated processing archiving \\
\hline 64 & cr.c.6. & $\begin{array}{l}\text { Chemistry \& } \\
\text { Environmental: }\end{array}$ & $\begin{array}{l}\text { Operate and Maintain Equipment/Systems: } \\
\text { > Operate Equipment/Systems }\end{array}$ & 0.18 & 27 & $\begin{array}{l}\text { In line monitors/equipment maint maintenance approx } 20 \text { per } \\
\text { day }\end{array}$ & $\begin{array}{l}\text { General CBP features, especially those that } \\
\text { enhance coordination with the Control Room }\end{array}$ \\
\hline 65 & CY.C.59a. & $\begin{array}{l}\text { Chemistry \& } \\
\text { Environmental: }\end{array}$ & $\begin{array}{l}\text { Operate and Maintain Equipment/Systems: } \\
>\text { Staff OCC and satellite control centers } \\
\text { for coordination of activities }\end{array}$ & 0.05 & $\$$ & $\begin{array}{l}\text { Item (1) from Opportunity Sheet; Estimated } 2 \text { persons in the OcC } \\
\text { and } 2 \text { in satellites ( } 2 \text { per shift } \times 2 \text { shifts }=4 \text { total); } 25 \% \text { of } \\
\text { outage days ( } 34 \text { days outage plus } 3 \text { days power assencion (37)); } \\
1.33 \text { outages per year; Estimate } 25 \% \text { of shift work is spent } \\
\text { gathering information; of that an } 80 \% \text { reduction in work due to } \\
\text { automation of status updates. }\end{array}$ & \begin{tabular}{|l|} 
Automated status updates \\
\end{tabular} \\
\hline 66 & CY.C.59b. & $\begin{array}{l}\text { Chemistry \& } \\
\text { Environmental: }\end{array}$ & $\begin{array}{l}\text { Operate and Maintain Equipment/Systems: } \\
>\text { Analysis work to resolve outage } \\
\text { schedule challenges }\end{array}$ & 0.03 & $\begin{aligned} 1 \\
2 \\
0 \\
0 \\
0 \\
i \\
0\end{aligned}$ & \begin{tabular}{|l} 
Item (2) from Opportunity Sheet; Estimated 2 persons in satellite \\
and 2 in the OCC ( 2 per shift 2 shifts $=4$ total); $25 \%$ of outage \\
days ( 34 days outage plus 3 days power assencion ( 377$) ; 1.33$ \\
outages per year; Esitmate $30 \%$ of shift work is spent analyzing \\
information; of that a $40 \%$ reduction in work due to advanced \\
data analytics
\end{tabular} & Advanced data analytics \\
\hline 67 & CY.C.59c. & $\begin{array}{l}\text { Chemistry \& } \\
\text { Environmental: }\end{array}$ & $\begin{array}{l}\text { Operate and Maintain Equipment/Systems: } \\
>\text { Conduct/Participate in outage } \\
\text { coordination meetings }\end{array}$ & 0.06 & 10 & $\begin{array}{l}\text { Ittem (3) from Opportunity Sheet; Estimated } 1 \text { person who } \\
\text { regularly attend coordination meetings; } 34 \text { days outage plus } 3 \\
\text { days power assencion ( } 37 \text { ); } 1.33 \text { outages per year; It is } \\
\text { estimated that networked collaboration tools that allow remote } \\
\text { access and participation in meetings will reduce workload1 by } \\
20 \%\end{array}$ & Networked meeting collaboration tools \\
\hline 68 & CY.C.59d. & $\begin{array}{l}\text { Chemistry \& } \\
\text { Environmental: }\end{array}$ & $\begin{array}{l}\text { Operate and Maintain Equipment/Systems: } \\
>\text { Outage general support (dispatchable } \\
\text { resources in field) }\end{array}$ & & & $\begin{array}{l}\text { Item (5) from Opportunity Sheet; Estimated } 4 \text { persons } 15 \% \text { more } \\
\text { effienct due to reduction in wait times due to microscheduling }\end{array}$ & Microscheduling \\
\hline 69 & EN.B.96. & Engineering: & $\begin{array}{l}\text { Monitor and report: } \\
>\text { Trend data }\end{array}$ & 2.09 & 3868 & $\begin{array}{l}8700 \text { surveillance conducted for Elec, I\&C, Mech, and Ops. } \\
\text { Estimate } 1 / 2 \text { hour saved by engineering time spent processing } \\
\text { data into trending databases (e.g., system health program). }\end{array}$ & Automated interface to databases. \\
\hline 70 & EN.C.59a. & Engineering: & $\begin{array}{l}\text { Perform Support Activities: } \\
>\text { Staff OCC and satellite control centers } \\
\text { for coordination of activities }\end{array}$ & 0.27 & 50 it & $\begin{array}{l}\text { Item (1) from Ooportunity Sheet; Estimated } 2 \text { persons in the OCC } \\
\text { and } 4 \text { i satellites ( } 3 \text { per shift } 2 \text { shifts = } 6 \text { total); } 20 \% \text { of } \\
\text { outage days ( } 34 \text { days outage plus } 3 \text { days power assencion (37)); } \\
1.33 \text { outages per year; Estimate } 20 \% \text { of shift work is spent } \\
\text { gathering information; of that an } 80 \% \text { reduction in work due to } \\
\text { automation of status updates. }\end{array}$ & Automated status updates \\
\hline
\end{tabular}




\begin{tabular}{|c|c|c|c|c|c|c|c|}
\hline \multicolumn{6}{|c|}{ Labor Cost Savings Summary Report } & \multicolumn{2}{|l|}{ Note: Highlighted rows are associated with $\mathrm{AOM}$ technologies } \\
\hline \# & $\begin{array}{c}\text { Task } \\
\text { Number }\end{array}$ & Functional Area & Work Category: Task & $\begin{array}{l}\text { EstFTE } \\
\text { Savings }\end{array}$ & $\begin{array}{c}\text { Est Labor } \\
\text { Savings } \\
(\times \$ 1,000)\end{array}$ & Basis for Calculation & Key Enabling Technologies \\
\hline 71 & EN.C.59b. & Engineering: & $\begin{array}{l}\text { Perform Support Activities: } \\
\text { > Analysis work to resolve outage } \\
\text { schedule challenges }\end{array}$ & 0.20 & 38 & $\begin{array}{l}\text { Item (2) from Opportunity Sheet; Estimated } 4 \text { persons in satellite } \\
\text { and } 2 \text { in the OCC ( } 3 \text { per shift } 2 \text { shifts = } 6 \text { total); } 34 \text { days outage } \\
\text { plus } 3 \text { days power assencion ( } 37 \text { ); } 1.33 \text { outages per year; } \\
\text { Esitmate } 30 \% \text { of shift work is spent analyzing information; of } \\
\text { that a } 40 \% \text { reduction in work due to advanced data analytics }\end{array}$ & Advanced data analytics \\
\hline 72 & EN.C.59c. & Engineering: & $\begin{array}{l}\text { Perform Support Activities: } \\
>\text { Conduct/Participate in outage } \\
\text { coordination meetings }\end{array}$ & 0.34 & 63 & $\begin{array}{l}\text { Item (3) from Opportunity Sheet; Estimated } 6 \text { persons who } \\
\text { regularly attend coordination meetings; } 34 \text { days outage plus } 3 \\
\text { days power assencion (37); } 1.33 \text { outages per year; It is } \\
\text { estimated that networked collaboration tools that allow remote } \\
\text { access and participation in meetings will reduce workload by } \\
20 \%\end{array}$ & Networked meeting collaboration tools \\
\hline 73 & EN.C.62. & Engineering: & $\begin{array}{l}\text { Perform Support Activities: } \\
>\text { Coordinate emergent activity requests }\end{array}$ & 0.26 & 47 & $\begin{array}{l}\text { Item (4) from Opportunity Sheet; Estimated } 9 \text { person, } 34 \text { days } \\
\text { outage plus } 3 \text { days power assencion ( } 377 \text {; } 1.33 \text { outages per hear; } \\
10 \% \text { reduction in time spent per issue using ad-hoc team } \\
\text { collaboration tools }\end{array}$ & Ad-hoc team collaboration tools \\
\hline 74 & TR.C.46a. & Training: & $\begin{array}{l}\text { Perform Support Activities: } \\
\text { > Print and assemble work packages }\end{array}$ & 0.19 & 13 & $\begin{array}{l}\text { Estimated } 200 \text { training days } \times 6 \text { disciplines (Elec, I\&C, Mech, } \\
\text { Ops, RP, and Chem) at } 2 \text { training activities requiring a package } \\
\text { per day (2,400 packages) }\end{array}$ & Automated CBP generation \\
\hline 75 & SY.A.119. & $\begin{array}{l}\text { Security \& Access } \\
\text { Authorization: }\end{array}$ & $\begin{array}{l}\text { Maintain Physical Security: } \\
>\text { Stand watch }\end{array}$ & 0.21 & 23 & $\begin{array}{l}\text { Item (5) from Opportunity Sheet; Estimated } 5 \text { persons } 15 \% \text { more } \\
\text { effienct due to reduction in wait times due to microscheduling }\end{array}$ & Microscheduling \\
\hline 76 & CA.A.126a. & $\begin{array}{l}\text { Corrective Action } \\
\text { Program: }\end{array}$ & \begin{tabular}{|l} 
Process Condition Reports: \\
> Processing condition reports
\end{tabular} & 1.15 & 178 & $\begin{array}{l}\text { Assumed 6,000 Condition Reports (CR) per year for a } 2 \text { unit } \\
\text { station. Estimate } 4 \text { hrs per report and elimination of } 10 \text { percent } \\
\text { of reports due to MWP/CBP features }\end{array}$ & $\begin{array}{l}\text { MWP/DBP features related to human error } \\
\text { reduction, such as smart data sheets, automated } \\
\text { computations, smart placekeeping, automated } \\
\text { component verification, etc. }\end{array}$ \\
\hline 77 & CA.A.126b. & $\begin{array}{l}\text { Corrective Action } \\
\text { Program: }\end{array}$ & $\begin{array}{l}\text { Process Condition Reports: } \\
\text { > Conduct Corrective Actions for } \\
\text { Condition Reports }\end{array}$ & 1.44 & 222 & $\begin{array}{l}\text { Assumed 3,000 condition reports result in required corrective } \\
\text { actions. Estimate } 10 \mathrm{hrs} \text { per CR for corrective actions and } \\
\text { elimination of } 10 \text { percent of CRs due to MWP/CBP features }\end{array}$ & $\begin{array}{l}\text { MWP/DBP features related to human error } \\
\text { reduction, such as smart data sheets, automated } \\
\text { computations, smart placekeeping, automated } \\
\text { component verification, etc. }\end{array}$ \\
\hline 78 & CA.A.127. & $\begin{array}{l}\text { Corrective Action } \\
\text { Program: }\end{array}$ & \begin{tabular}{|l} 
Process Condition Reports: \\
> Apparent Cause Evaluations
\end{tabular} & 0.24 & 37 & $\begin{array}{l}\text { Assumed } 250 \text { condition reports result in apparent cause } \\
\text { evaluations. Estimate } 20 \mathrm{hrs} \text { per evaluation and elimination of } \\
10 \text { percent of CRs due to MWP/CBP features }\end{array}$ & $\begin{array}{l}\text { MWP/DBP features related to human error } \\
\text { reduction, such as smart data sheets, automated } \\
\text { computations, smart placekeeping, automated } \\
\text { component verification, etc. }\end{array}$ \\
\hline 79 & CA.A.128. & $\begin{array}{l}\text { Corrective Action } \\
\text { Program: }\end{array}$ & $\begin{array}{l}\text { Process Condition Reports: } \\
>\text { Root Cause Evaluations }\end{array}$ & 0.42 & 77 & $\begin{array}{l}\text { Assumed } 30 \text { condition reports result in root cause evaluations. } \\
\text { Estimate } 720 \mathrm{hrs} \text { per evaluation and elimination of } 10 \text { percent } \\
\text { of CRs due to MWP/CBP features }\end{array}$ & $\begin{array}{l}\text { MWP/DBP features related to human error } \\
\text { reduction, such as smart data sheets, automated } \\
\text { computations, smart placekeeping, automated } \\
\text { component verification, etc. }\end{array}$ \\
\hline 80 & CA.B.125. & $\begin{array}{l}\text { Corrective Action } \\
\text { Program: }\end{array}$ & $\begin{array}{l}\text { Process Outage Related Events: } \\
>\text { Manage/administer investigation (e.g. } \\
\text { PI) }\end{array}$ & 0.72 & 133 & $\begin{array}{l}\text { Assume 2-3 highly significant events per outage - one is } \\
\text { avoidable with intelligent plant data and real time configuration } \\
\text { awareness }\end{array}$ & Intelligent plant configuration software \\
\hline
\end{tabular}

